\title{
SYNTHESIS OF SCEPTRIN ALKALOIDS
}

Vladimir B. Birman* and Xun-Tian Jiang

A contribution from the Department of Chemistry, Washington University, Campus Box 1134, One Brookings Drive, Saint Louis, Missouri 63130.

SUPPORTING INFORMATION: Experimental procedures ( 8 pages), ${ }^{1} \mathrm{H}$ NMR and ${ }^{13} \mathrm{C}$ NMR spectra (35 pages).

\section{Experimental Part.}

General. All reagents were used as received from commercial sources, unless specified otherwise, or prepared as described in the literature. Reactions were monitored by thin layer chromatography (TLC) using EM Science 60F silica gel plates. Flash column chromatography was performed over ICN Ecochrom silica gel (32-63 $\square \mathrm{m})$. Reactions requiring anhydrous conditions were performed in vacuum heat-dried glassware under nitrogen atmosphere. Reaction mixtures were stirred magnetically. Tetrahydrofuran and toluene were distilled from sodium and benzophenone immediately before use. Dichloromethane and DMF were distilled from $\mathrm{CaH}_{2}$. ${ }^{1} \mathrm{H}$ NMR and ${ }^{13} \mathrm{C}$ NMR spectra were recorded using a Varian Unity Plus-300 spectrometer (at $300 \mathrm{MHz}$ and $75 \mathrm{MHz}$, respectively) and a Varian Unity Inova-600 spectrometer (at $600 \mathrm{MHz}$ and $125 \mathrm{MHz}$, respectively). The chemical shifts are reported as $\square$ values (ppm) relative to TMS. Infrared spectra were recorded on a Perkin-Elmer Spectrum Bx using thin film technique and $\mathrm{NaCl}$ plates. Low-resolution electron impact mass spectra $(\mathrm{m} / \mathrm{z})$ were recorded on a Finnigan LCQ-Classic Ion-Trap mass spectrometer using electrospray ionization (ESI). High-Resolution mass spectral analyses were performed on a Kratos MS-50TA spectrometer using the fast atom bombardment method (FAB), and Micromass QTOF-Ultima quadrupole-TOF mass spectrometer with electrospray ionization (ESI). Melting points were measured on a Mel-Temp II capillary melting point apparatus and are uncorrected.
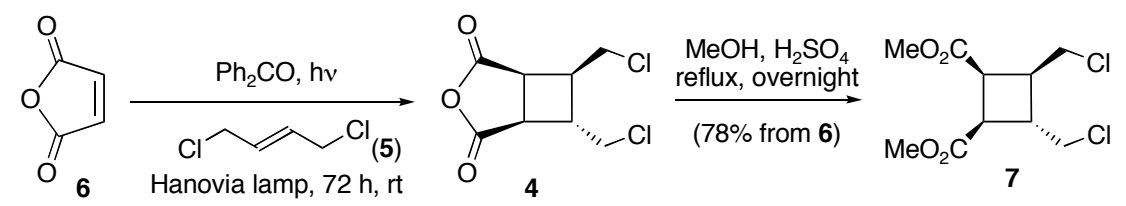

\section{3,4-Bis-chloromethyl-cyclobutane-1,2-dicarboxylic acid dimethyl ester (7)}

A procedure similar to that reported by Wissner and Meinwald ${ }^{11}$ was followed, except for the esterification step. A solution of maleic anhydride $6(1.57 \mathrm{~g}, 16.0 \mathrm{mmol})$ and benzophenone $(0.728 \mathrm{~g}, 4.00 \mathrm{mmol})$ in trans-1,4-dichloro-2-butene $5(20.0 \mathrm{~g}, 160 \mathrm{mmol})$ was degassed with $\mathrm{N}_{2}$ and loaded into 15 NMR tubes. The tubes were arranged around a 450-W Hanovia lamp in a water-cooled Pyrex immersion well and the mixture was irradiated at room temperature for 72 hours. The contents of the tubes were combined; the unreacted $\mathbf{5}$ was recovered by distillation under reduced pressure and used in subsequent runs without additional purification. The residue was refluxed with $26 \mathrm{~mL}$ of methanol in the presence of 3 drops of conc. $\mathrm{H}_{2} \mathrm{SO}_{4}$ overnight. The methanol was evaporated under reduced pressure and the residue was dissolved in ether (100

\section{S1}


$\mathrm{mL}$ ), which was washed with saturated aqueous $\mathrm{NaHCO}_{3}$ and brine. The organic phase was dried $\left(\mathrm{Na}_{2} \mathrm{SO}_{4}\right)$, and evaporated to dryness. The residue was purified by flash column chromatography with ethyl acetate/hexanes (1/6, v/v) to afford $7(3.36 \mathrm{~g}, 78 \%)$ as clear oil.

${ }^{1}$ H NMR (300 MHz, $\left.\mathrm{CDCl}_{3}\right)$ : $\square 3.74-3.78(\mathrm{~m}, 1 \mathrm{H}), 3.68(\mathrm{~s}, 3 \mathrm{H}), 3.65-3.69(\mathrm{~m}, 1 \mathrm{H}), 3.64(\mathrm{~s}, 3 \mathrm{H})$, $3.60(\mathrm{~s}, 1 \mathrm{H}), 3.57(\mathrm{~s}, 1 \mathrm{H}), 3.42-3.50(\mathrm{~m}, 1 \mathrm{H}), 3.18(\mathrm{dd}, \mathrm{J}=0.7,2 \mathrm{~Hz}, 1 \mathrm{H}), 3.15$ (dd, J = 0.7, 2 $\mathrm{Hz}, 1 \mathrm{H}), 2.78-2.89$ (m, 1H); ${ }^{13} \mathbf{C}$ NMR $\left(75 \mathrm{MHz}, \mathrm{CDCl}_{3}\right)$ : $\square$ 171.9, 171.5, 52.0, 51.9, 46.5, 43.3, 42.9, 41.8, 38.4, 38.1; IR (neat) 2998, 2953, 2848, 1736, 1436, 1369, 1329, 1252, 1202, 1174, 1112, 1048, 968; HRMS (FAB) $\mathrm{m} / \mathrm{z}\left[(\mathrm{M}+\mathrm{Li})^{+}\right]\left(\mathrm{C}_{10} \mathrm{H}_{14} \mathrm{Cl}_{2} \mathrm{O}_{4} \mathrm{Li}\right)$ calculated 275.0429 , found 275.0431 .

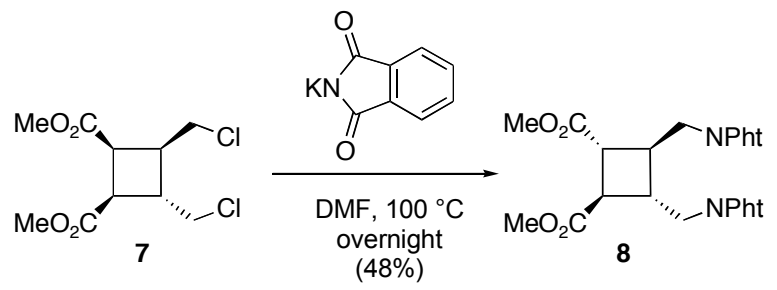

\section{3,4-Bis-(N-phthalimidomethyl)-cyclobutane-1,2-dicarboxylic acid dimethyl ester (8)}

A mixture of 7 (6.30 g, $23.4 \mathrm{mmol})$, potassium phthalimide $(17.3 \mathrm{~g}, 93.7 \mathrm{mmol})$ and $\mathrm{KI}(7.80$ g, $46.8 \mathrm{mmol})$ and DMF $(78 \mathrm{~mL})$ was stirred at $100{ }^{\circ} \mathrm{C}$ overnight. The reaction mixture was poured into water $(400 \mathrm{~mL})$, and the aqueous layer was extracted with ethyl acetate. The combined organic extracts were washed with saturated brine, dried $\left(\mathrm{Na}_{2} \mathrm{SO}_{4}\right)$, and concentrated to dryness. The residue was purified by flash column chromatography with ethyl acetate/hexanes $(1 / 1, \mathrm{v} / \mathrm{v})$ to afford $\mathbf{8}(5.50 \mathrm{~g}, 48 \%)$ as a white solid, $\mathbf{m p ~} 81-83^{\circ} \mathrm{C}$.

${ }^{1} \mathbf{H}$ NMR (300 MHz, $\mathrm{CDCl}_{3}$ ): $\square$ 7.76-7.79 (m, 4H), 7.64-7.67 (m, 4H), 3.73-3.87 (m, 4H), 3.38 $(\mathrm{s}, 6 \mathrm{H}), 3.08\left(\mathrm{~A}_{2} \mathrm{~B}_{2}, \mathrm{~J}=2.6,9.3 \mathrm{~Hz}, 2 \mathrm{H}\right), 2.58-2.64(\mathrm{~m}, 2 \mathrm{H}) ;{ }^{13} \mathbf{C} \mathbf{N M R}\left(75 \mathrm{MHz}, \mathrm{CDCl}_{3}\right)$ : 172.0, 168.2, 133.8, 131.9, 123.2, 51.9, 41.1, 40.4, 33.8; IR (neat) 3462, 2928, 2853, 1770, 1713, 1613, 1467, 1430, 1395,6, 1360, 1266, 1189, 1066, 1016, 929; I R (neat) 3464, 2952, 1771, 1713, 1613, 1467, 1434, 1395, 1367, 1333, 1234, 1189, 1087, 1069, 1033, 998, 920; HRMS (ESI) $\mathrm{m} / \mathrm{z}\left[(\mathrm{M}+\mathrm{H})^{+}\right]\left(\mathrm{C}_{26} \mathrm{H}_{23} \mathrm{~N}_{2} \mathrm{O}_{8}\right)$ calculated 491.1454, found 491.1446.

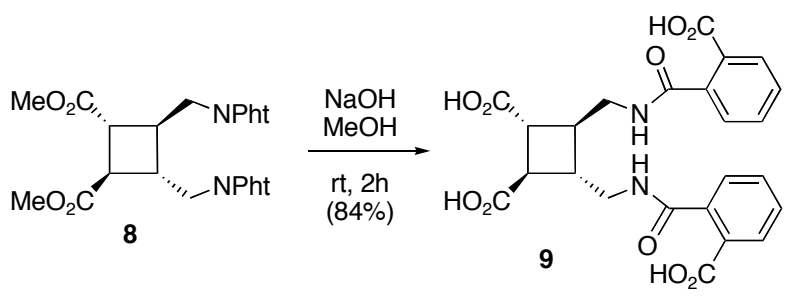

\section{3,4-Bis-[(2-carboxy-benzoylamino)-methyl]-cyclobutane-1,2-dicarboxylic acid (9)}

A mixture of $8(100 \mathrm{mg}, 0.204 \mathrm{mmol}), \mathrm{NaOH}(80 \mathrm{mg}, 2.0 \mathrm{mmol}) \mathrm{H}_{2} \mathrm{O}(0.5 \mathrm{~mL})$ and $\mathrm{MeOH}(5$ $\mathrm{mL}$ ) is stirred at $\mathrm{rt}$ for $2 \mathrm{~h}$. The reaction mixture was then adjusted with $2 \mathrm{~N} \mathrm{HCl}$ to $\mathrm{pH} 4$ and evaporated to dryness. The residue was washed with $\mathrm{MeOH}(0.6 \mathrm{~mL}, 3$ times). The $\mathrm{MeOH}$ was removed to give $9(85 \mathrm{mg}, 84 \%)$ as a white solid, $\mathbf{m p} 88-90{ }^{\circ} \mathrm{C}$.

${ }^{1}$ H NMR (300 MHz, CD $\left.{ }_{3} \mathrm{OD}\right)$ : $\square 7.74-7.77(\mathrm{~m}, 2 \mathrm{H}), 7.40-7.53(\mathrm{~m}, 6 \mathrm{H}), 3.67$ (dd, J = 6.5, 13.6 $\mathrm{Hz}, 2 \mathrm{H}), 3.44(\mathrm{dd}, \mathrm{J}=6.5,13.6 \mathrm{~Hz}, 2 \mathrm{H}), 2.92\left(\mathrm{~A}_{2} \mathrm{~B}_{2}, \mathrm{~J}=2.9,9.2 \mathrm{~Hz}, 2 \mathrm{H}\right), 2.55-2.58(\mathrm{~m}, 2 \mathrm{H})$; ${ }^{13}$ C NMR (75 MHz, $\left.\mathrm{CD}_{3} \mathrm{OD}\right): \square$ 176.4, 172.9, 170.0, 139.4, 132.8, 131.2, 131.1, 130.6, 128.7, 44.0, 42.3, 41.1; IR (neat) 3417 (br), 2626, 2359, 2078, 1704, 1633, 1555, 1488, 1434, 1274, 
1143, 1082, 1015; HRMS (ESI) $\mathrm{m} / \mathrm{z}\left[(\mathbf{M}+\mathbf{H})^{+}\right]\left(\mathrm{C}_{24} \mathrm{H}_{23} \mathrm{~N}_{2} \mathrm{O}_{10}\right)$ calculated : 499.1353, found 499.1365 .
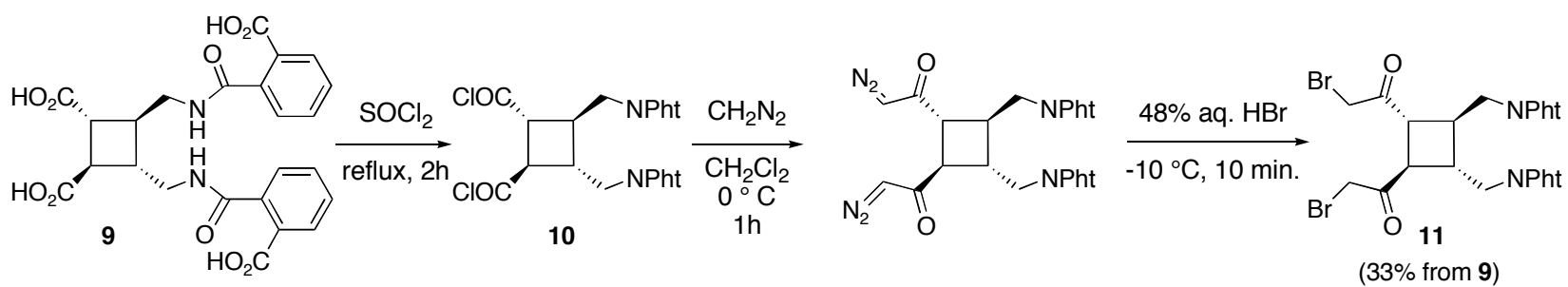

\section{1,2-Bis-bromoacetyl-3,4-bis-(N-phthalimidomethyl)-cyclobutane (11)}

A mixture of $9(4.38 \mathrm{~g}, 8.8 \mathrm{mmol})$ and $\mathrm{SOCl}_{2}(19.3 \mathrm{~mL}, 264 \mathrm{mmol})$ was refluxed for $2 \mathrm{~h}$. The excess of $\mathrm{SOCl}_{2}$ was removed under reduced pressure. The residue was co-evaporated with toluene $(5 \mathrm{~mL}) 3$ times. The crude acyl chloride was dissolved in $\mathrm{CH}_{2} \mathrm{Cl}_{2}(10 \mathrm{~mL})$ and added dropwise at $-10{ }^{\circ} \mathrm{C}$ to a solution of $\mathrm{CH}_{2} \mathrm{~N}_{2}$ in $\mathrm{CH}_{2} \mathrm{Cl}_{2}(200 \mathrm{~mL})$ prepared from N-nitroso-Nmethylurea $(23.7 \mathrm{~g}, 0.230 \mathrm{~mol})$ and $40 \% \mathrm{KOH}(60 \mathrm{~mL})$ and dried with $\mathrm{KOH}$ pellets for $3 \mathrm{~h}$. The reaction mixture was stirred at $0{ }^{\circ} \mathrm{C}$ for $1 \mathrm{~h}$ and concentrated to a volume of about $80 \mathrm{~mL}$. To this solution was added dropwise aqueous conc. $\mathrm{HBr}(48 \%, 10 \mathrm{~mL}, 88 \mathrm{mmol})$ at $-10{ }^{\circ} \mathrm{C}$. The reaction mixture was stirred at the same temperature for $10 \mathrm{~min}$, washed with saturated aqueous $\mathrm{NaHCO}_{3}$ and brine. The organic phase was dried $\left(\mathrm{Na}_{2} \mathrm{SO}_{4}\right)$, and concentrated to dryness. The residue was purified by flash column chromatography with ethyl acetate/hexanes $(1 / 10, \mathrm{v} / \mathrm{v})$ to afford 11 (1.79 g, 33\% overall yield) as a white solid, mp $112-115{ }^{\circ} \mathrm{C}$.

${ }^{1} \mathbf{H}$ NMR (300 MHz, $\left.\mathrm{CDCl}_{3}\right)$ : $\square$ 7.78-7.81 (m, 4H), 7.69-7.71 (m, 4H), 4.09 (s, 4H), 3.81-3.84 $(\mathrm{m}, 4 \mathrm{H}), 3.32\left(\mathrm{~A}_{2} \mathrm{~B}_{2}, \mathrm{~J}=2.5,9.7 \mathrm{~Hz}, 2 \mathrm{H}\right), 2.33-2.53(\mathrm{~m}, 2 \mathrm{H}) ;{ }^{13} \mathbf{C} \mathbf{N M R}\left(75 \mathrm{MHz}, \mathrm{CDCl}_{3}\right)$ : $\square$ 199.4, 168.6, 134.2, 131.7, 123.5, 45.3, 39.3, 38.8, 33.8; IR (neat) 3462, 2928, 2853, 1770, 1713, 1613, 1467, 1430, 1395, 6, 1360, 1266, 1189, 1066, 1016, 929; HRMS (ESI) m/z [(M+H) ${ }^{+}$ $\left(\mathrm{C}_{26} \mathrm{H}_{21} \mathrm{Br}_{2} \mathrm{~N}_{2} \mathrm{O}_{6}\right)$ calculated 614.9766, found 614.9772.
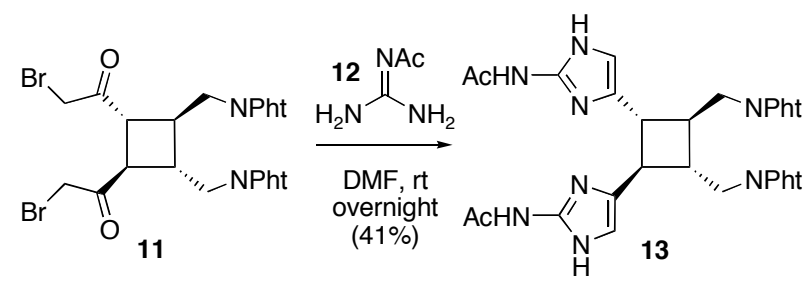

1,2-Bis-(2-acetylamino-1H-imidazol-4-yl)-3,4-bis-(N-phthalimidomethyl)-cyclobutane (13)

A solution of $11(1.6 \mathrm{~g}, 2.6 \mathrm{mmol})$ and $\mathrm{N}$-acetylguanidine $12(1.6 \mathrm{~g}, 15.8 \mathrm{mmol})$ in DMF (8.7 $\mathrm{mL}$ ) was stirred at $\mathrm{rt}$ overnight. The DMF was removed under reduced pressure. The residue was treated with acetone-water $(1: 1,10 \mathrm{~mL})$ to give suspension, and the acetone was evaporated. The precipitate was collected by filtration, washed with water $(10 \mathrm{~mL}, 3$ times) and ethyl acetate (10 $\mathrm{mL}, 3$ times) to give 13 as a white solid $(0.66 \mathrm{~g}, 41 \%), \mathbf{m p} 202-205^{\circ} \mathrm{C}$ (dec).

${ }^{1}$ H NMR (600 MHz, DMSO-d $)$ ): $\square 11.14$ (s, 2H), 11.11 (s, 2H), 7.62-7.80 (m, 4H), 7.43-7.56 (m, $4 \mathrm{H}), 3.43-3.74(\mathrm{~m}, 4 \mathrm{H}), 2.98\left(\mathrm{~A}_{2} \mathrm{~B}_{2}, \mathrm{~J}=1.9,8.6 \mathrm{~Hz}, 2 \mathrm{H}\right), 2.48(\mathrm{~m}, 2 \mathrm{H}), 2.00(\mathrm{~s}, 6 \mathrm{H}) ;{ }^{13} \mathbf{C} \mathbf{N M R}$ (125 MHz, DMSO-d $)$ : $\square$ 168. 1, 167.7, 140.6, 137.3, 134.1, 131.1, 122.5, 108.2, 42.4, 41.2, 40.7, 22.6; IR (neat) 3333 (br), 2359, 1769, 1712, 1613, 1467, 1433, 1396, 1188, 1069, 1026, 928; HRMS (ESI) m/z [(M+H $\left.)^{+}\right]\left(\mathrm{C}_{32} \mathrm{H}_{29} \mathrm{~N}_{8} \mathrm{O}_{6}\right)$ calculated 621.2210, found 621.2214. 


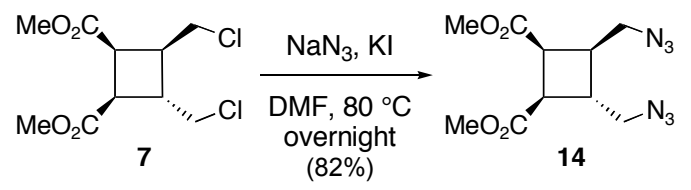

\section{3,4-Bis-azidomethyl-cyclobutane-1,2-dicarboxylic acid dimethyl ester (14)}

A mixture of 7 (6.35 g, $23.6 \mathrm{mmol}), \mathrm{NaN}_{3}(9.20 \mathrm{~g}, 142 \mathrm{mmol})$ and $\mathrm{KI}(7.84 \mathrm{~g}, 47.2 \mathrm{mmol})$ and DMF $(78 \mathrm{~mL})$ was stirred at $80{ }^{\circ} \mathrm{C}$ overnight. The reaction mixture was poured into water $(400 \mathrm{~mL})$, and the aqueous layer was extracted with ethyl acetate. The combined organic extracts were washed with saturated brine, dried $\left(\mathrm{Na}_{2} \mathrm{SO}_{4}\right)$, and concentrated to dryness. The residue was purified by flash column chromatography with ethyl acetate/hexanes $(1 / 10, \mathrm{v} / \mathrm{v})$ to afford $\mathbf{1 4}$ $(5.46 \mathrm{~g}, 82 \%)$ as clear oil.

${ }^{1} \mathbf{H}$ NMR $\left(300 \mathrm{MHz}, \mathrm{CDCl}_{3}\right)$ : $\mathrm{\square} 3.68(\mathrm{~s}, 3 \mathrm{H}), 3.64(\mathrm{~s}, 3 \mathrm{H}), 3.43-3.48(\mathrm{~m}, 2 \mathrm{H}), 3.43-3.48(\mathrm{~m}, 3 \mathrm{H})$, $3.05(\mathrm{t}, \mathrm{J}=9.8 \mathrm{~Hz}, 1 \mathrm{H}), 2.89-2.99(\mathrm{~m}, 1 \mathrm{H}), 2.49-2.61(\mathrm{~m}, 1 \mathrm{H}) ;{ }^{13} \mathbf{C}$ NMR $\left(75 \mathrm{MHz}, \mathrm{CDCl}_{3}\right)$ : 171.9, 171.6, 52.8, 52.0, 51.8, 51.1, 41.5, 40.4, 38.7, 35.6; IR (neat) 2953, 2100, 1731, 1436, 1354, 1204, 1171, 1065, 1020, 924; HRMS (FAB) m/z [(M+Li $\left.)^{+}\right]\left(\mathrm{C}_{10} \mathrm{H}_{14} \mathrm{~N}_{6} \mathrm{O}_{4} \mathrm{Li}\right)$ calculated 289.1237 , found 289.1249 .

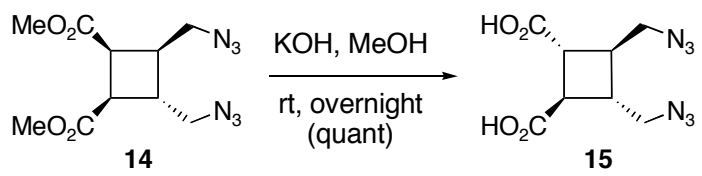

\section{3,4-Bis-azidomethyl-cyclobutane-1,2-dicarboxylic acid (15)}

A solution of $14(5.1 \mathrm{~g}, 18 \mathrm{mmol})$ and $\mathrm{KOH}(10.0 \mathrm{~g}, 178 \mathrm{mmol})$ in $\mathrm{MeOH}(90 \mathrm{~mL})$ was stirred at rt overnight. The $\mathrm{MeOH}$ was removed under reduced pressure, and the residue was dissolved in water $(100 \mathrm{~mL})$. The aqueous phase was extracted with ethyl acetate which was discarded. The aqueous phase was acidified to $\mathrm{pH} 4$ with conc. $\mathrm{HCl}$ and extracted with ethyl acetate. The combined organic extract was washed with saturated brine, dried $\left(\mathrm{Na}_{2} \mathrm{SO}_{4}\right)$, and concentrated to give $\mathbf{1 5}(4.57 \mathrm{~g}, 100 \%)$ as clear oil.

${ }^{1}$ H NMR (300 MHz, CD $\left.{ }_{3} \mathrm{OD}\right):$ ] 3.43-3.56 (m, 4H), $2.95\left(\mathrm{~A}_{2} \mathrm{~B}_{2}, \mathrm{~J}=2.2,9.1 \mathrm{~Hz}, 2 \mathrm{H}\right), 2.39-2.42$ (m, 2H); ${ }^{13} \mathrm{C}$ NMR (75 MHz, CD $\left.\mathrm{OD}\right)$ : $\square$ 176.6, 54.5, 42.5, 40.0; IR (neat) 2926, 2100, 1708, 1249; HRMS (ESI) $\mathrm{m} / \mathrm{z}\left[(\mathbf{M}+\mathbf{N a})^{+}\right]\left(\mathrm{C}_{8} \mathrm{H}_{10} \mathrm{~N}_{6} \mathrm{O}_{4} \mathrm{Na}\right)$ calculated 277.0661, found 277.0667.
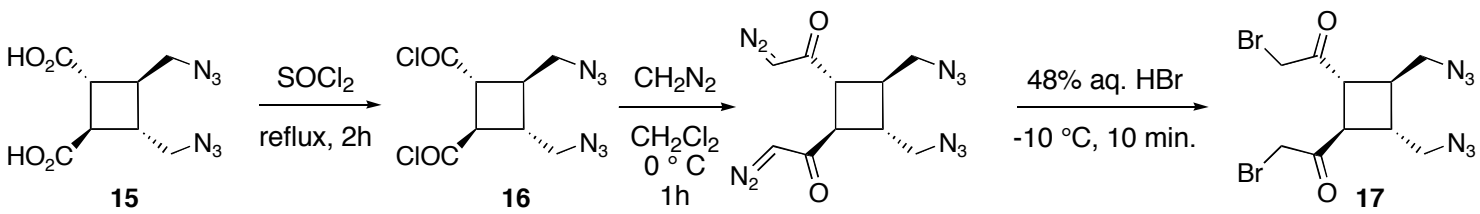

(72\% from 14)

\section{1,2-Bis-bromoacetyl-3,4-bis-azidomethylcyclobutane (17)}

A mixture of $15(4.57 \mathrm{~g}, 18 \mathrm{mmol})$ and $\mathrm{SOCl}_{2}(39.4 \mathrm{~mL}, 540 \mathrm{mmol})$ was refluxed for $2 \mathrm{~h}$. The excess of $\mathrm{SOCl}_{2}$ was removed under reduced pressure. The residue was coevaporated with toluene $(5 \mathrm{~mL}) 3$ times. The crude acyl chloride was dissolved in $\mathrm{CH}_{2} \mathrm{Cl}_{2}(10 \mathrm{~mL})$ and added dropwise at $-10{ }^{\circ} \mathrm{C}$ to a solution of $\mathrm{CH}_{2} \mathrm{~N}_{2}$ in $\mathrm{CH}_{2} \mathrm{Cl}_{2}(400 \mathrm{~mL})$ prepared from N-Nitroso-Nmethylurea $(51.5 \mathrm{~g}, 0.500 \mathrm{~mol})$ and $40 \% \mathrm{KOH}(154 \mathrm{~mL})$ and dried with $\mathrm{KOH}$ pellets for $3 \mathrm{~h}$. 
The reaction mixture was stirred at $0{ }^{\circ} \mathrm{C}$ for $1 \mathrm{~h}$ and concentrated to a volume of about $100 \mathrm{~mL}$. To this solution was added dropwise aqueous conc. $\mathrm{HBr}(48 \%, 9.23 \mathrm{~mL}, 90 \mathrm{mmol})$ at $-10{ }^{\circ} \mathrm{C}$. The reaction mixture was stirred at the same temperature for $10 \mathrm{~min}$, washed with saturated aqueous $\mathrm{NaHCO}_{3}$ and brine. The organic phase was dried $\left(\mathrm{Na}_{2} \mathrm{SO}_{4}\right)$, and concentrated to dryness. The residue was purified by flash column chromatography with ethyl acetate/hexanes (1/10, v/v) to afford 17 (5.29 g, 72\% overall yield) as clear oil.

${ }^{1} \mathbf{H}$ NMR $\left(300 \mathrm{MHz}, \mathrm{CDCl}_{3}\right)$ : $\square 3.95(\mathrm{~s}, 4 \mathrm{H}), 3.48-3.53(\mathrm{~m}, 6 \mathrm{H}), 2.39$ - $2.46(\mathrm{~m}, 2 \mathrm{H}) ;{ }^{13} \mathbf{C ~ N M R}$ (75 MHz, $\mathrm{CDCl}_{3}$ ): $\square$ 199.5, 53.3, 44.9, 38.1, 32.8; IR (neat) 2931, 2100, 1709, 1386, 1262; HRMS $(\mathrm{FAB}) \mathrm{m} / \mathrm{z}\left[(\mathbf{M}+\mathbf{L i})^{+}\right]\left(\mathrm{C}_{10} \mathrm{H}_{12} \mathrm{Br}_{2} \mathrm{~N}_{6} \mathrm{O}_{2} \mathrm{Li}\right)$ calculated 412.9548, found 412.9547 .
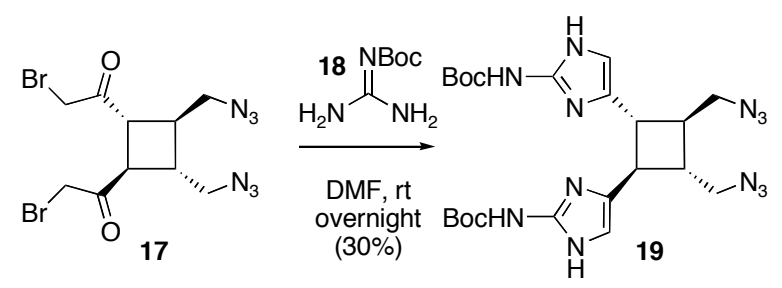

\section{1,2-Bis-(2-tert-butoxycarbonylamino-1H-imidazol-4-yl)-3,4-bis-azidomethyl-cyclobutane} (19)

A solution of $17(3.8 \mathrm{~g}, 9.3 \mathrm{mmol})$ and $\mathbf{1 8}^{14}(8.80 \mathrm{~g}, 55.9 \mathrm{mmol})$ in DMF (31 mL) was stirred at $\mathrm{rt}$ overnight. The DMF was removed under reduced pressure. The residue was treated with ethyl acetate. The precipitate was collected by filtration, washed with ethyl acetate $(10 \mathrm{~mL}, 3$ times) to give $19(1.5 \mathrm{~g}, 30 \%)$ as a white solid, $\mathbf{m p} 192-194{ }^{\circ} \mathrm{C}(\mathrm{dec})$.

${ }^{1} \mathbf{H}$ NMR (300 MHz, CDCl +1 drop of HOAc): $\square 6.51$ (s, 2H), 3.48-3.50 (m, 4H), $2.98\left(\mathrm{~A}_{2} \mathrm{~B}_{2}, \mathrm{~J}\right.$ $=2.7,9.1 \mathrm{~Hz}, 2 \mathrm{H}), 2.34-2.41(\mathrm{~m}, 2 \mathrm{H}), 1.53(\mathrm{~s}, 18 \mathrm{H}) ;{ }^{13} \mathbf{C} \mathbf{N M R}\left(75 \mathrm{MHz}, \mathrm{CDCl}_{3}+1\right.$ drop of HOAc): $\square 151.3,148.5,133.5,106.8,86.0,53.8,41.3,38.5,27.7$; IR (neat) 3298 (br), 1733, 1630, 1357, 1256, 1157, 1124; HRMS (ESI) m/z $\left[(\mathbf{M}+\mathbf{H})^{+}\right]\left(\mathrm{C}_{22} \mathrm{H}_{33} \mathrm{~N}_{12} \mathrm{O}_{4}\right)$ calculated 529.2748, found 529.2737 .
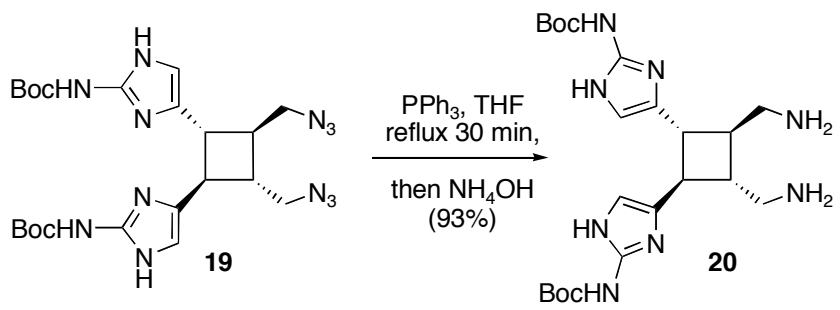

\section{1,2-Bis-(2-tert-butoxycarbonylamino-1H-imidazol-4-yl)-3,4-bis-aminomethyl-cyclobutane (20)}

A mixture of 19 (200 mg, $0.380 \mathrm{mmol})$ and $\mathrm{PPh}_{3}(398 \mathrm{mg}, 1.52 \mathrm{mmol})$ in THF (4 mL) was refluxed for $30 \mathrm{~min}$, whereupon it became homogeneous. To the reaction mixture was added $\mathrm{NH}_{4} \mathrm{OH}(20 \%, 0.5 \mathrm{~mL})$, the reflux was continued for $10 \mathrm{~min}$, and the mixture was concentrated to dryness. The residue was purified by flash column chromatography with $\mathrm{CH}_{2} \mathrm{Cl}_{2} / \mathrm{MeOH}$ saturated with $\mathrm{NH}_{3}(1 / 1, \mathrm{v} / \mathrm{v})$ to afford 20 (169 mg, 93\% yield) as a white solid, $\mathbf{m p ~} 158-160{ }^{\circ} \mathrm{C}$ (dec).

${ }^{1}$ H NMR (300 MHz, CD $\left.\mathrm{OD}\right): \square 6.68(\mathrm{~s}, 2 \mathrm{H}), 2.85\left(\mathrm{~A}_{2} \mathrm{~B}_{2}, \mathrm{~J}=2.4,9.0 \mathrm{~Hz}, 2 \mathrm{H}\right), 2.74-2.82(\mathrm{~m}$, 4H), 2.07 - $2.10(\mathrm{~m}, 2 \mathrm{H}), 1.59$ (s, 18H); ${ }^{13} \mathrm{C}$ NMR (75 MHz, CD $\left.\mathrm{OD}\right): \square$ 152.4, 150.6, 140.4, 
107.6, 86.1, 48.1, 46.6, 41.5, 28.1; IR (neat) 3298 (br), 1733, 1630, 1357, 1256, 1157, 1124; HRMS (ESI) $\mathrm{m} / \mathrm{z}\left[(\mathrm{M}+\mathrm{H})^{+}\right]\left(\mathrm{C}_{22} \mathrm{H}_{37} \mathrm{~N}_{8} \mathrm{O}_{4}\right)$ calculated 477.2938, found 477.2945.
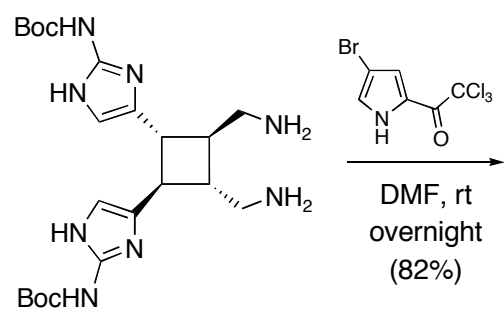

20

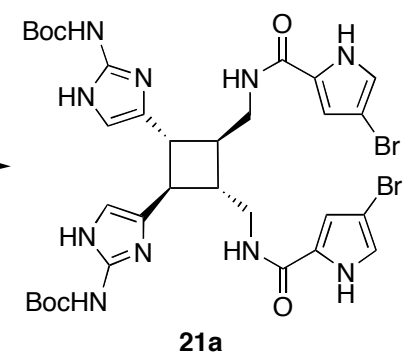

\section{1,2-Bis-(2-tert-butoxycarbonylamino-1H-imidazol-4-yl)-3,4-bis-\{[(4-bromo-1H-pyrrole-2- carbonyl)-amino]-methyl\}-cyclobutane (21a)}

A solution of 20 ( $150 \mathrm{mg}, 0.315 \mathrm{mmol}$ ) and 2-trichloroacetyl-4-bromopyrrole ${ }^{15}$ (368 mg, 1.26 mmol) in DMF (1 mL) was stirred at $\mathrm{rt}$ overnight. The DMF was removed under reduced pressure. The residue was purified by flash column chromatography with $\mathrm{CH}_{2} \mathrm{Cl}_{2} / \mathrm{MeOH}$ saturated with $\mathrm{NH}_{3}(40 / 1, \mathrm{v} / \mathrm{v})$ to give $21 \mathrm{a}(212 \mathrm{mg}, 82 \%)$ as a white solid, $\mathbf{m p}>196^{\circ} \mathrm{C}(\mathrm{dec})$. ${ }^{1} \mathrm{H}$ NMR $\left(300 \mathrm{MHz}, \mathrm{CD}_{3} \mathrm{OD}\right): \square 6.91(\mathrm{~d}, \mathrm{~J}=1.6 \mathrm{~Hz}, 2 \mathrm{H}), 6.80(\mathrm{~d}, \mathrm{~J}=1.6 \mathrm{~Hz}, 2 \mathrm{H}), 6.61(\mathrm{~s}, 2 \mathrm{H})$, 3.43-3.53 (m, 4H), $2.92\left(\mathrm{~A}_{2} \mathrm{~B}_{2}, \mathrm{~J}=2.7,9.2 \mathrm{~Hz}, 2 \mathrm{H}\right), 2.28-2.32(\mathrm{~m}, 2 \mathrm{H}), 1.57(\mathrm{~s}, 18 \mathrm{H}) ;{ }^{13} \mathbf{C} \mathbf{~ N M R}$ (75 MHz, $\mathrm{CD}_{3} \mathrm{OD}$ ): $\square 162.7,152.3,150.5,139.6,127.6,122.7,113.3,107.8,97.4,86.1,43.7$, 43.2, 41.5, 28.1; IR (neat) 3298, 1736, 1624, 1457, 1371, 1258, 1156, 1126, 921; HRMS (ESI) $\mathrm{m} / \mathrm{z}\left[(\mathbf{M}+\mathbf{H})^{+}\right]\left(\mathrm{C}_{32} \mathrm{H}_{41} \mathrm{Br}_{2} \mathrm{~N}_{10} \mathrm{O}_{6}\right)$ calculated 819.1577, found 819.1572.

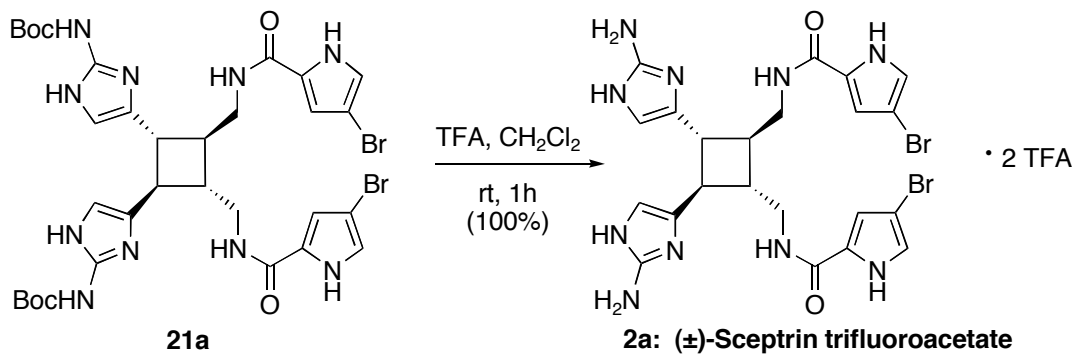

\section{Sceptrin (2a)}

A solution of $21 \mathrm{a}(147 \mathrm{mg}, 0.179 \mathrm{mmol})$ in $50 \%$ TFA in $\mathrm{CH}_{2} \mathrm{Cl}_{2}(2 \mathrm{~mL})$ was stirred at $\mathrm{rt}$ for 1 $\mathrm{h}$. The reaction mixture was concentrated to give sceptrin trifluoroacetate $(152 \mathrm{mg}, 100 \%)$ as a white solid, $\mathbf{m p} 152-154^{\circ} \mathrm{C}$.

${ }^{1}$ H NMR (300 MHz, CD $\left.\mathrm{OD}\right): \square 6.91(\mathrm{~d}, 1.4 \mathrm{~Hz}, 2 \mathrm{H}), 6.75$ (d, $\left.1.4 \mathrm{~Hz}, 2 \mathrm{H}\right), 6.56(\mathrm{~s}, 2 \mathrm{H}), 3.48-$ $3.50(\mathrm{~m}, 4 \mathrm{H}), 2.99\left(\mathrm{~A}_{2} \mathrm{~B}_{2}, 2.5,9.5 \mathrm{~Hz}\right), 2.34-2.37(\mathrm{~m}, 2 \mathrm{H}) ;{ }^{13} \mathbf{C} \mathbf{N M R}\left(75 \mathrm{MHz}, \mathrm{CD}_{3} \mathrm{OD}\right)$ : 163.0, 148.9, 128.7, 127.2, 123.0, 113.4, 110.2, 97.5, 44.2, 42.3, 39.2; IR (neat) 3151, 2360, $2341,1681,1557,1435,1320,1201,1137$.

The free base of sceptrin was obtained by treatment of sceptrin $\bullet 2 \mathrm{TFA}$ with 3 eq of $\mathrm{KOH}$ in $\mathrm{MeOH}$ followed by flash column chromatography with $\mathrm{CH}_{2} \mathrm{Cl}_{2} / \mathrm{MeOH}$ saturated with $\mathrm{NH}_{3}(1 / 1$, $\mathrm{v} / \mathrm{v})$ as a white solid, $\mathbf{m p}>192^{\circ} \mathrm{C}(\mathrm{dec})$.

${ }^{1} \mathrm{H}$ NMR $\left(300 \mathrm{MHz}, \mathrm{CD}_{3} \mathrm{OD}\right): \square 6.91(\mathrm{~d}, \mathrm{~J}=1.4 \mathrm{~Hz}, 2 \mathrm{H}), 6.82(\mathrm{~d}, \mathrm{~J}=1.4 \mathrm{~Hz}, 2 \mathrm{H}), 6.31(\mathrm{~s}, 2 \mathrm{H})$, $3.41-3.55(\mathrm{~m}, 4 \mathrm{H}), 3.02\left(\mathrm{~A}_{2} \mathrm{~B}_{2}, \mathrm{~J}=2.6,9.4 \mathrm{~Hz}, 2 \mathrm{H}\right), 2.16-2.26(\mathrm{~m}, 2 \mathrm{H}) ;{ }^{13} \mathbf{C}$ NMR $(75 \mathrm{MHz}$, 
$\mathrm{CD}_{3} \mathrm{OD}$ ): $\square 161.7,149.5,133.9,126.4,121.5,112.3,110.9,96.3,43.3,42.1,40.6$; IR (neat) 3287 (br), 2359, 2340, 1622, 1568, 1521, 1455, 1386, 1327, 1129, 921, HRMS (ESI) $\mathrm{m} / \mathrm{z}\left[(\mathbf{M}+\mathbf{H})^{+}\right]$ $\left(\mathrm{C}_{22} \mathrm{H}_{25} \mathrm{Br}_{2} \mathrm{~N}_{10} \mathrm{O}_{2}\right)$ calculated 619.0565, found 619.0557.

For comparison with the ${ }^{1} \mathrm{H}$ NMR spectra of synthetic and natural sceptrin $\bullet \mathrm{HCl}$ reported by Baran's group, ${ }^{12}$ sceptrin hydrochloride was obtained by addition of $2 \mathrm{~N} \mathrm{HCl} \mathrm{in} \mathrm{Et}_{2} \mathrm{O}$ to the free base in $\mathrm{MeOH}$ followed by evaporation to dryness. White solid, mp $216-220^{\circ} \mathrm{C}(\mathrm{dec})$.

${ }^{1} \mathrm{H}$ NMR $\left(300 \mathrm{MHz}, \mathrm{D}_{2} \mathrm{O}\right): \square 7.00(\mathrm{~d}, \mathrm{~J}=1.6 \mathrm{~Hz}, 2 \mathrm{H}), 6.56(\mathrm{~d}, \mathrm{~J}=1.6 \mathrm{~Hz}, 2 \mathrm{H}), 6.53(\mathrm{~s}, 2 \mathrm{H}), 3.40$ $-3.52(\mathrm{~m}, 4 \mathrm{H}), 2.98\left(\mathrm{~A}_{2} \mathrm{~B}_{2}, \mathrm{~J}=2.4,9.6 \mathrm{~Hz}, 2 \mathrm{H}\right), 2.46-2.48(\mathrm{~m}, 2 \mathrm{H})$.

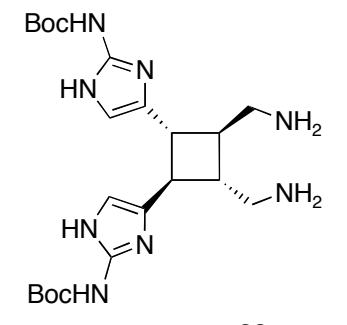

20

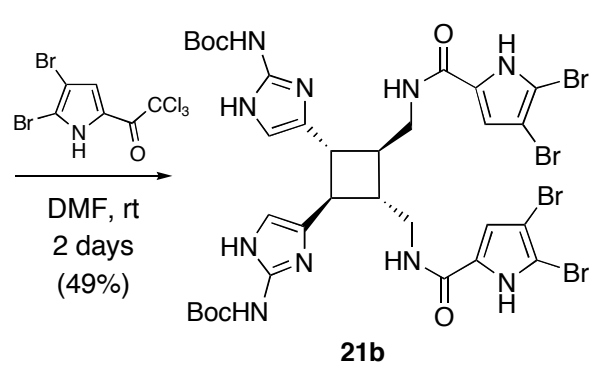

21b

\section{1,2-Bis-(2-tert-butoxycarbonylamino-1H-imidazol-4-yl)-3,4-bis--\{[(4,5-dibromo-1H- pyrrole-2-carbonyl)-amino]-methyl\}-cyclobutane (21b)}

A solution of $\mathbf{2 0}(136 \mathrm{mg}, 0.286 \mathrm{mmol})$ and 2-trichloroacetyl-4,5-dibromopyrrole ${ }^{16}(423 \mathrm{mg}$, $1.14 \mathrm{mmol})$ in DMF $(1 \mathrm{~mL})$ was stirred at $\mathrm{rt}$ for 2 days. The DMF was removed under reduced pressure. The residue was purified by flash column chromatography with $\mathrm{CH}_{2} \mathrm{Cl}_{2} / \mathrm{MeOH}$ saturated with $\mathrm{NH}_{3}(40 / 1, \mathrm{v} / \mathrm{v})$ to give $\mathbf{2 1 b}(137 \mathrm{mg}, 49 \%)$ as a white solid, $\mathbf{m p}>194{ }^{\circ} \mathrm{C}(\mathrm{dec})$.

${ }^{1} \mathbf{H}$ NMR (300 MHz, CD $\left.{ }_{3} \mathrm{OD}\right)$ : $\square 6.78(\mathrm{~s}, 2 \mathrm{H}), 6.56(\mathrm{~s}, 2 \mathrm{H}), 3.40-3.44(\mathrm{~m}, 4 \mathrm{H}), 2.88\left(\mathrm{~A}_{2} \mathrm{~B}_{2}, \mathrm{~J}\right.$ $=2.2,9.3 \mathrm{~Hz}, 2 \mathrm{H}), 2.18-2.29(\mathrm{~m}, 2 \mathrm{H}), 1.54(\mathrm{~s}, 18 \mathrm{H}) ;{ }^{13} \mathbf{C} \mathbf{~ N M R}\left(75 \mathrm{MHz}, \mathrm{CD}_{3} \mathrm{OD}\right)$ : $\square$ 161.9, $152.3,150.5,139.8,128.9,114.3,107.8,105.9,99.9,86.1,43.6,43.3,41.6,28.1$; IR (neat) 1730, $1621,1557,1523,1416,1350,1241,1154,1120 ;$ HRMS (ESI) m/z $\left[(\mathbf{M}+\mathbf{H})^{+}\right]\left(\mathrm{C}_{32} \mathrm{H}_{39} \mathrm{Br}_{4} \mathrm{~N}_{10} \mathrm{O}_{6}\right)$ calculated 974.9787 , found 974.9760 .

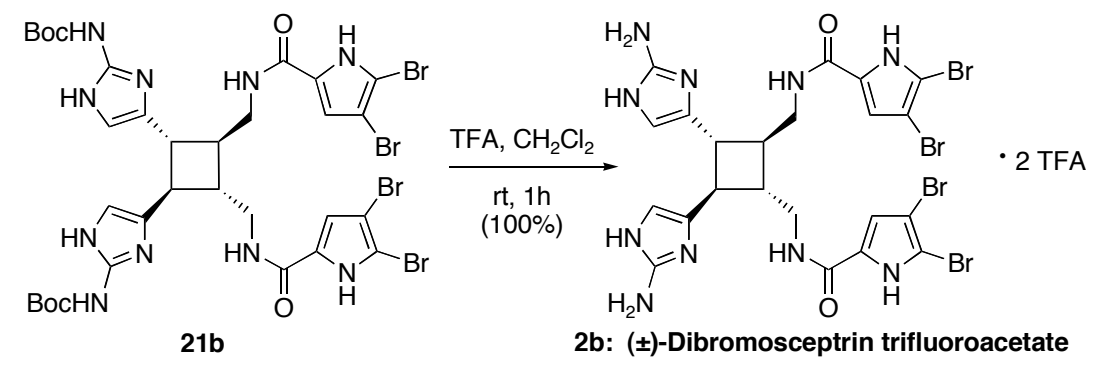

\section{Dibromosceptrin (2b)}

A solution of $21 \mathbf{b}(82 \mathrm{mg}, 0.084 \mathrm{mmol})$ in $50 \%$ TFA in $\mathrm{CH}_{2} \mathrm{Cl}_{2}(2 \mathrm{~mL})$ was stirred at $\mathrm{rt}$ for 1 $\mathrm{h}$. The reaction mixture was concentrated to give dibromosceptrin $\bullet 2 \mathrm{TFA}(84 \mathrm{mg}, 100 \%)$ as a white solid, $\mathbf{m p} 100-102^{\circ} \mathrm{C}$.

${ }^{1}$ H NMR (300 MHz, CD $\left.{ }_{3} \mathrm{OD}\right)$ : $66.77(\mathrm{~s}, 2 \mathrm{H}), 6.56(\mathrm{~s}, 2 \mathrm{H}), 3.47-3.49(\mathrm{~m}, 4 \mathrm{H}), 2.99\left(\mathrm{~A}_{2} \mathrm{~B}_{2}, \mathrm{~J}\right.$ $=2.6,9.6 \mathrm{~Hz}, 2 \mathrm{H}), 2.34-2.37(\mathrm{~m}, 2 \mathrm{H}) ;{ }^{13} \mathbf{C} \mathbf{~ N M R}\left(75 \mathrm{MHz}, \mathrm{CD}_{3} \mathrm{OD}\right): \square$ 162.1, 149.0, 128.7, 
128.5, 114.4, 110.2, 106.4, 100.1, 44.1, 42.4, 39.2; IR (neat) 3168 (br), 2360, 1681, 1567, 1529, $1417,1326,1201,1141,1022,979$.

The free base of dibromosceptrin was obtained by treatment of dibromosceptrin $\bullet 2$ TFA with 3 eq of $\mathrm{KOH}$ in $\mathrm{MeOH}$ followed by flash column chromatography with $\mathrm{CH}_{2} \mathrm{Cl}_{2} / \mathrm{MeOH}$ saturated with $\mathrm{NH}_{3}(1 / 3$ to $1 / 1, \mathrm{v} / \mathrm{v})$ as a white solid, $\mathbf{m p}>202^{\circ} \mathrm{C}(\mathrm{dec})$.

${ }^{1} \mathbf{H}$ NMR (300 MHz, CD $\left.{ }_{3} \mathrm{OD}\right): \square 6.81$ (s, 2H), 6.28 (s, 2H), 3.38 - 3.49 (m, 4H), $2.89\left(\mathrm{~A}_{2} \mathrm{~B}_{2}, \mathrm{~J}\right.$ $=2.9,9.2 \mathrm{~Hz}, 2 \mathrm{H}), 2.20-2.23(\mathrm{~m}, 2 \mathrm{H}) ;{ }^{13} \mathbf{C} \mathbf{N M R}\left(75 \mathrm{MHz}, \mathrm{CD}_{3} \mathrm{OD}\right): \square$ 162.2, 150.7, 135.1, 129.0, 114.5, 112.2, 106.4, 99.7, 44.5, 43.3, 41.7; IR (neat) 3320 (br), 2360, 2340, 1621, 1568, 1418; HRMS (ESI) m/z [(M+H) $\left.{ }^{+}\right]\left(\mathrm{C}_{22} \mathrm{H}_{23} \mathrm{Br}_{4} \mathrm{~N}_{10} \mathrm{O}_{2}\right)$ calculated 774.8739 , found 774.8740 .

For comparison with the ${ }^{1} \mathrm{H}$ NMR and ${ }^{13} \mathrm{C}$ NMR data of natural dibromosceptrin $\bullet 2 \mathrm{HOAc}$ reported by Keifer's group, ${ }^{5}$ dibromosceptrin $\cdot 2 \mathrm{HOAc}$ in $\mathrm{CD}_{3} \mathrm{OD}$ was obtained by titration of the free base in $\mathrm{CD}_{3} \mathrm{OD}$ with $\mathrm{HOAc}$ in $\mathrm{CD}_{3} \mathrm{OD}$ monitored by ${ }^{1} \mathrm{H}$ NMR.

${ }^{1} \mathbf{H}$ NMR (300 MHz, CD OD): $\square 6.81$ (s, 2H), 6.51 (s, 2H), 3.48-3.49 (m, 4H), 2.99 (dd, $\mathrm{A}_{2} \mathrm{~B}_{2}, \mathrm{~J}$ $=2.6,9.5 \mathrm{~Hz}, 2 \mathrm{H}), 2.33-2.36(\mathrm{~m}, 2 \mathrm{H}), 1.95(\mathrm{~s}, 6 \mathrm{H}) ;{ }^{13} \mathbf{C}$ NMR $\left(75 \mathrm{MHz}, \mathrm{CD}_{3} \mathrm{OD}\right): \square 180.1,162.1$, $149.4,129.7,128.6,114.5,110.1,106.2,100.0,44.2,42.4,39.5,23.9$.

Table 1. ${ }^{1} \mathrm{H}$ NMR ${ }^{13} \mathrm{C}$ NMR Data for Synthetic and Natural Dibromosceptrin $\bullet 2 \mathrm{HOAc}$

\begin{tabular}{lllllll}
\hline \multirow{2}{*}{ Synthetic } & $\begin{array}{l}6.81 \\
(\mathrm{~s}, 2 \mathrm{H})\end{array}$ & $\begin{array}{l}6.51 \\
(\mathrm{~s}, 2 \mathrm{H})\end{array}$ & $\begin{array}{l}3.48-3.49 \\
(\mathrm{~m}, 4 \mathrm{H})\end{array}$ & $\begin{array}{l}2.99 \\
(\mathrm{dd}, 2 \mathrm{H})\end{array}$ & $\begin{array}{l}2.33-2.36 \\
(\mathrm{~m}, 2 \mathrm{H})\end{array}$ & $\begin{array}{l}1.95 \\
(\mathrm{~s}, 6 \mathrm{H})\end{array}$ \\
\hline \multirow{2}{*}{ Natural } & 6.81 & 6.52 & 3.48 & 3.00 & 2.35 & 1.93 \\
& $(\mathrm{~s}, 2 \mathrm{H})$ & $(\mathrm{s}, 2 \mathrm{H})$ & $\begin{array}{l}\text { (br s, 4H) } \\
(\mathrm{m}, 2 \mathrm{H})\end{array}$ & $\begin{array}{l}(\mathrm{br} \mathrm{s}, 2 \mathrm{H}) \\
(\mathrm{s}, 6 \mathrm{H})\end{array}$ \\
\hline
\end{tabular}

Table 2. ${ }^{13} \mathrm{C}$ NMR Data for Synthetic and Natural Dibromosceptrin•2HOAc*

\begin{tabular}{llllllllllllll}
\hline Synthetic & 180.1 & 162.1 & 149.4 & 129.7 & 128.6 & 114.5 & 110.1 & 106.2 & 100.0 & 44.2 & 42.4 & 39.5 & 23.9 \\
\hline Natural & 180.1 & 162.0 & 149.2 & 128.7 & 128.5 & 114.7 & 110.1 & 106.3 & 100.1 & 44.2 & 42.5 & 39.1 & 24.0 \\
\hline
\end{tabular}

$*$ The ${ }^{13} \mathrm{C}$ NMR chemical shifts of dibromosceptrin $\bullet 2 H O A c$ are concentration-dependent, and up to $0.5 \mathrm{ppm}$ differences were observed at different concentrations. 


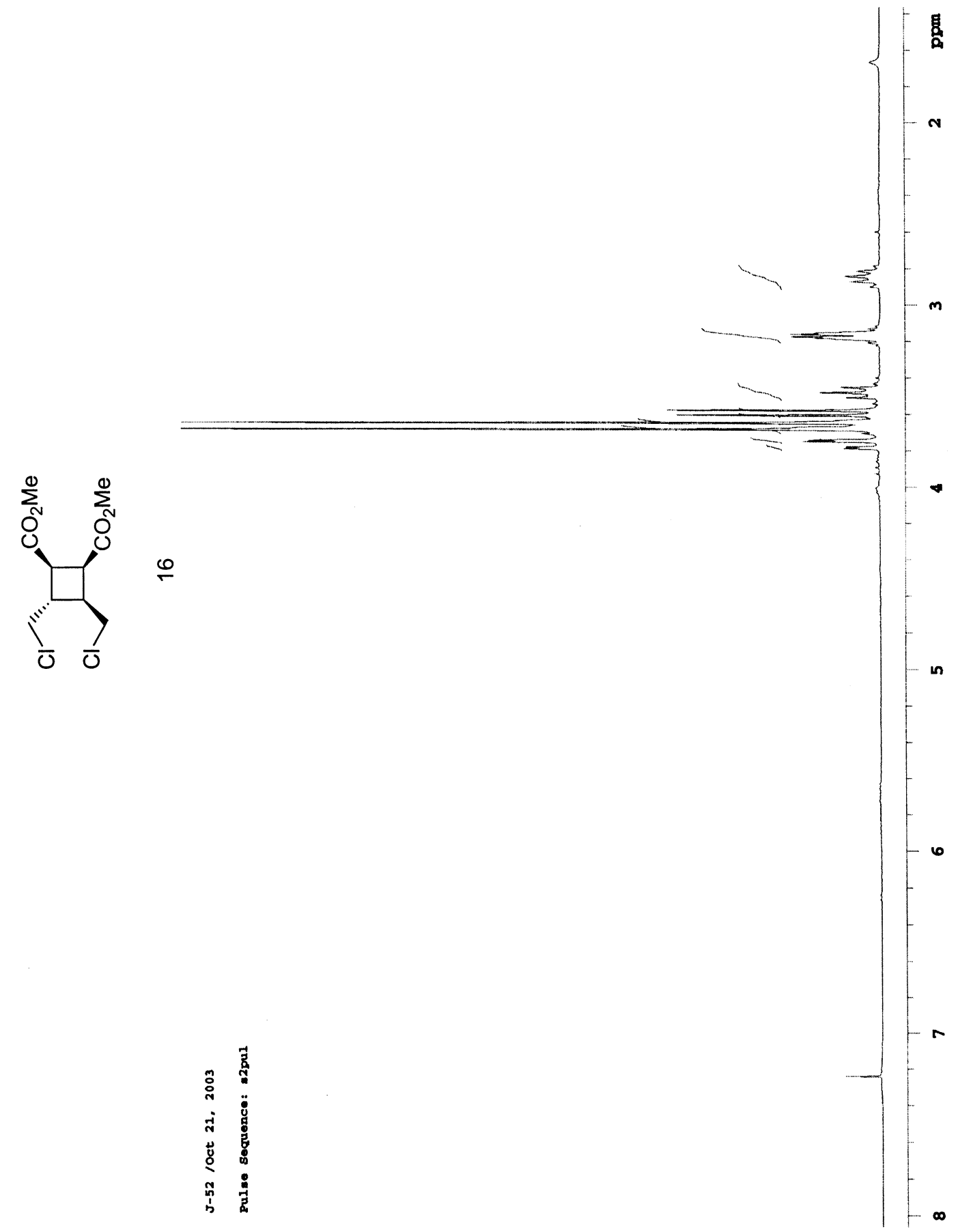

S9 

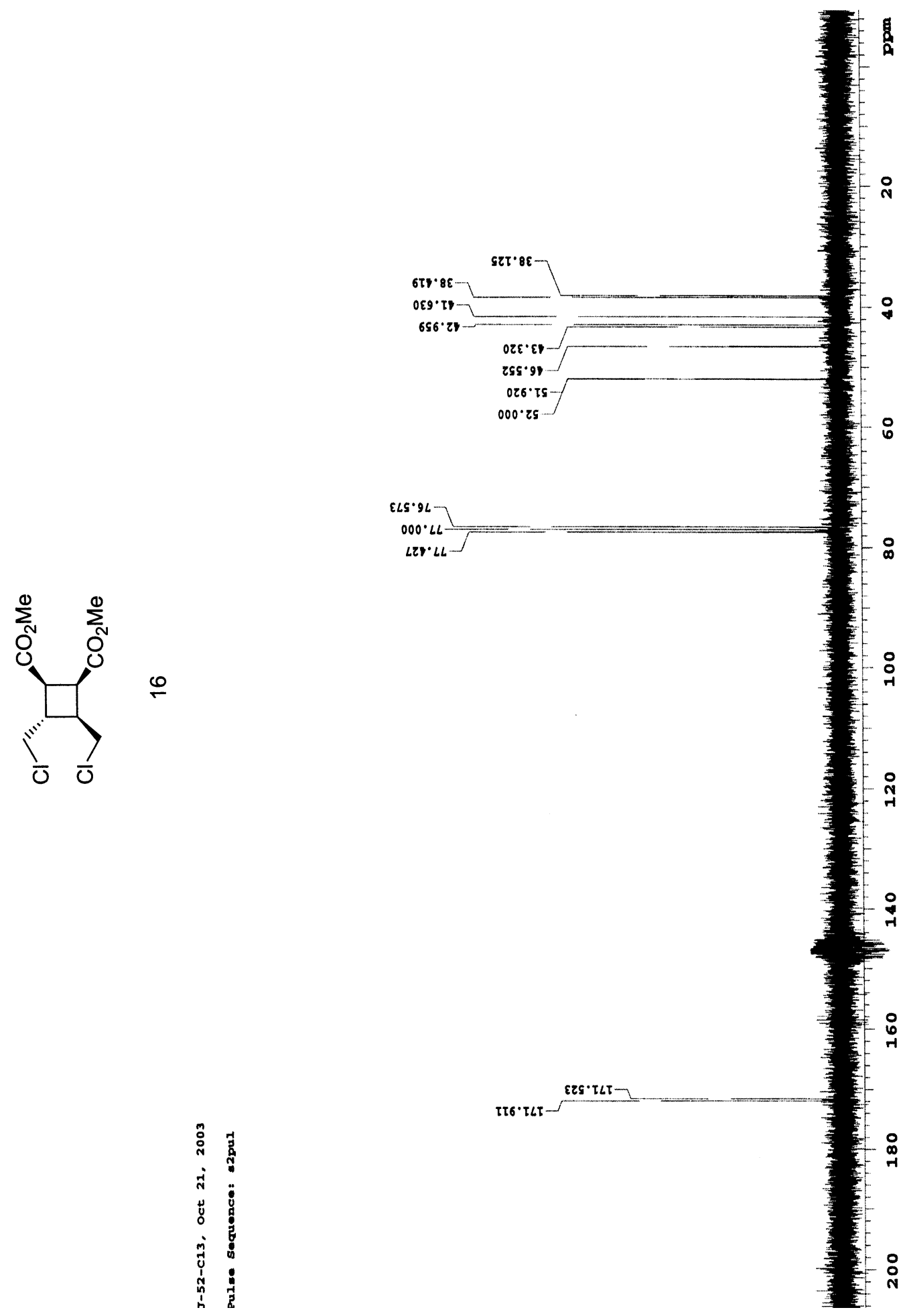

S10 


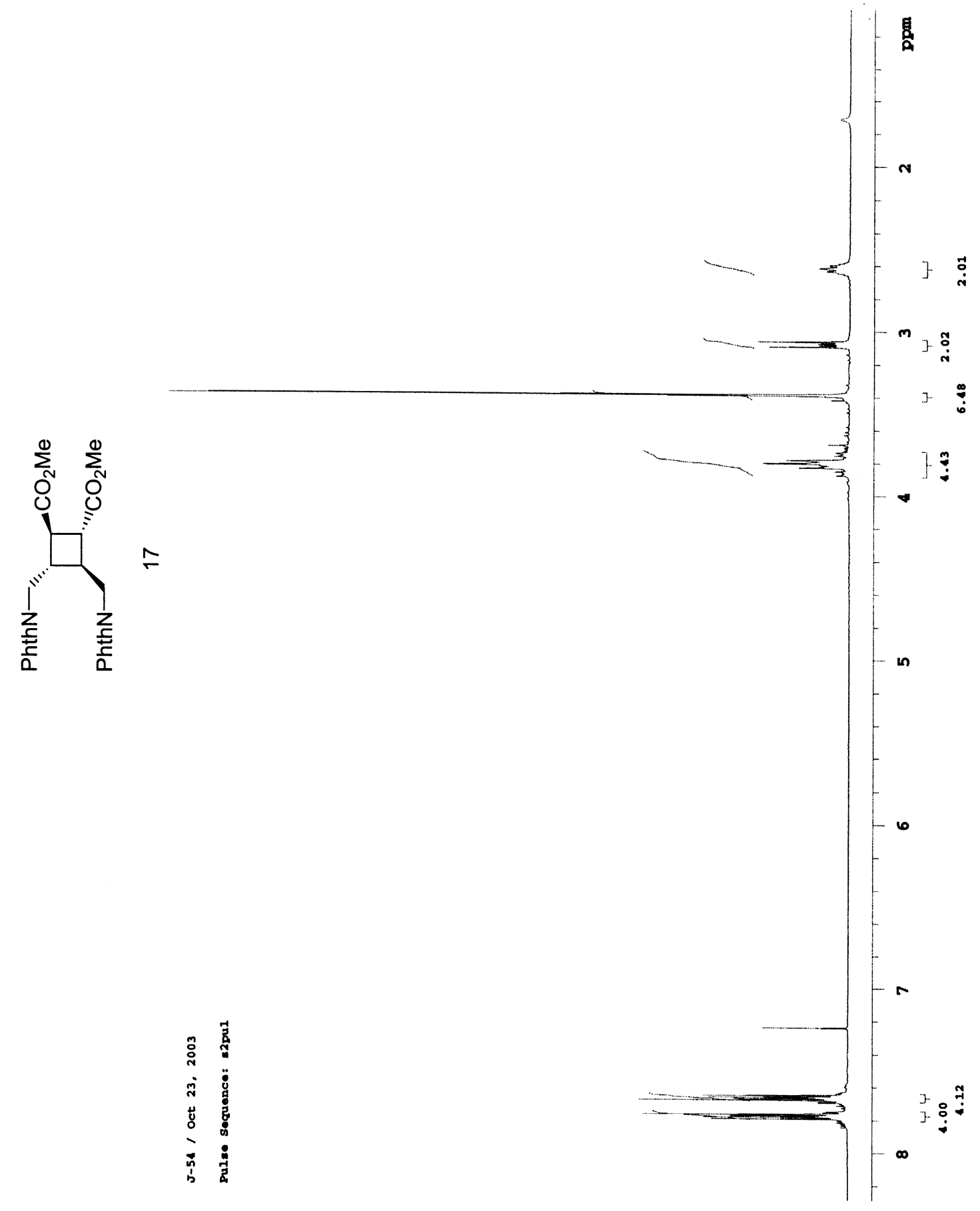

S11 


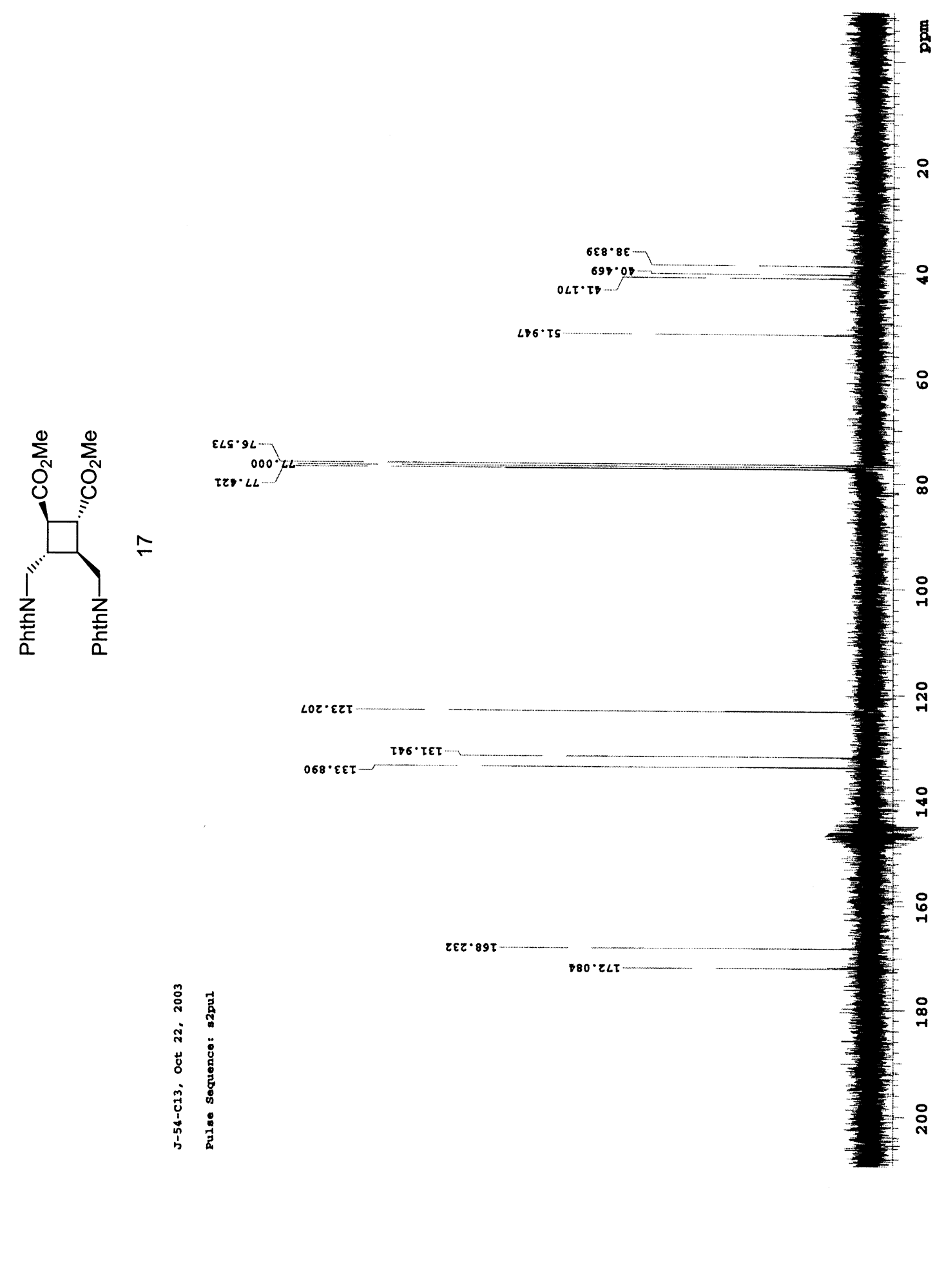




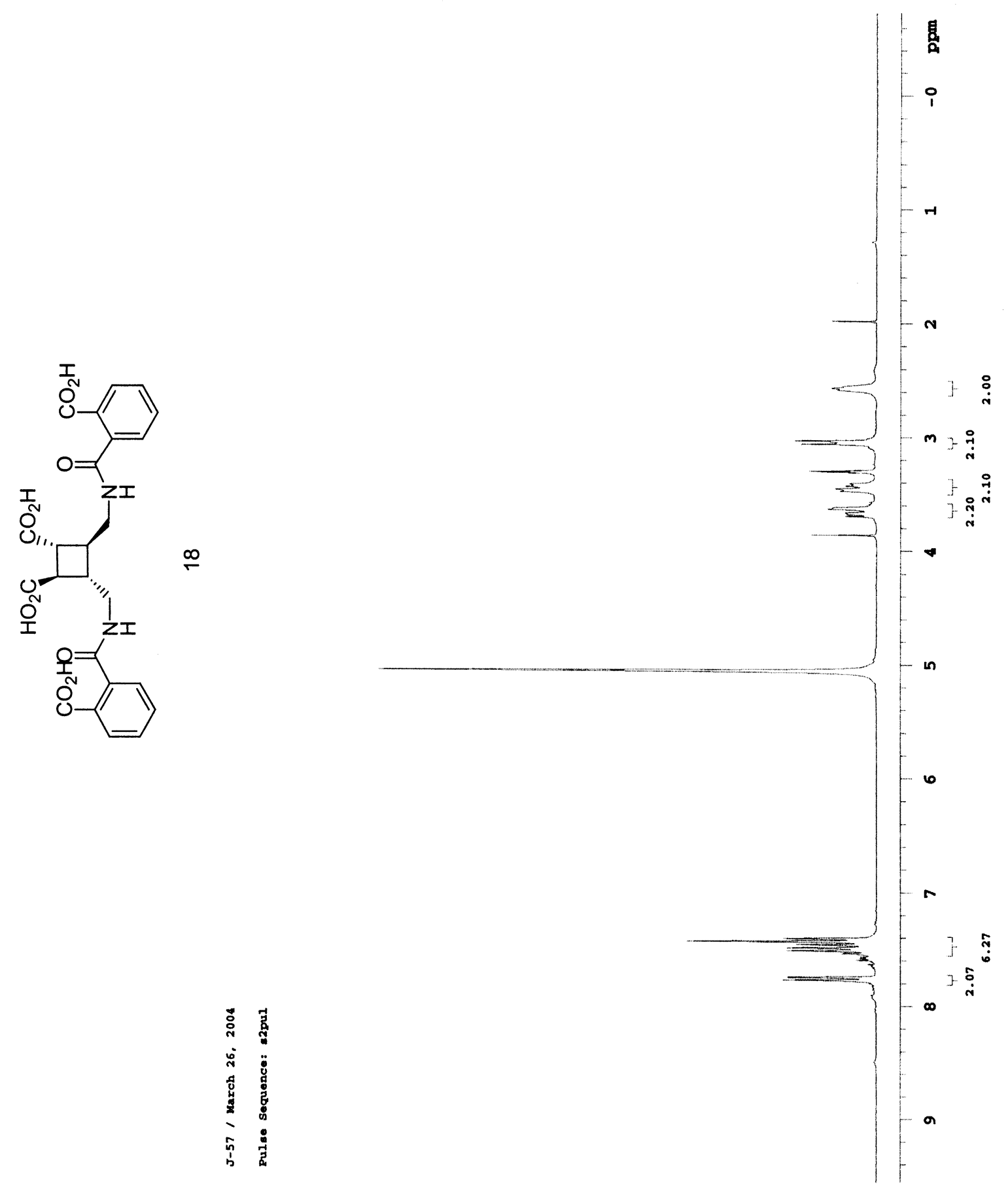

$\mathrm{S} 13$ 


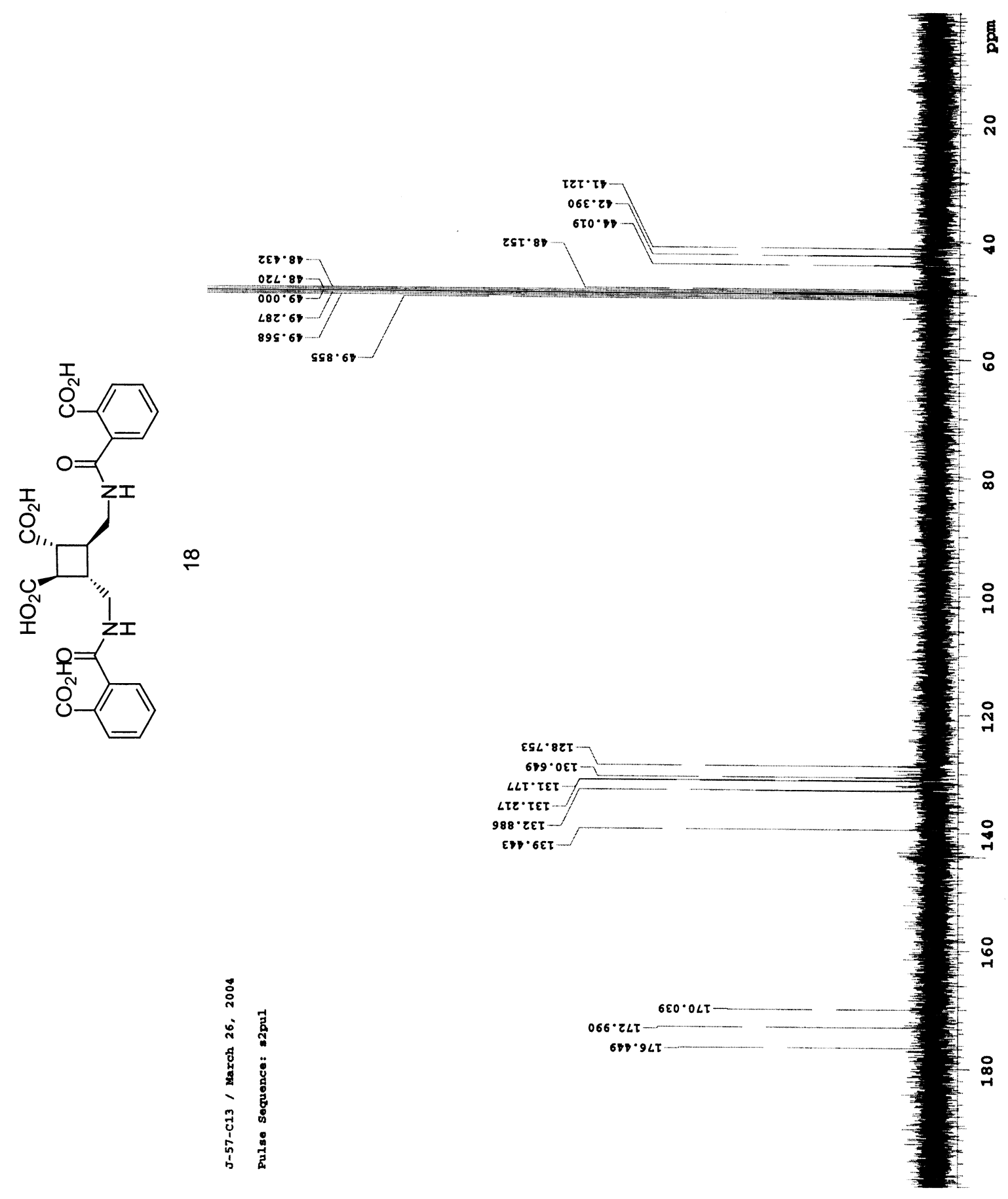

S14 


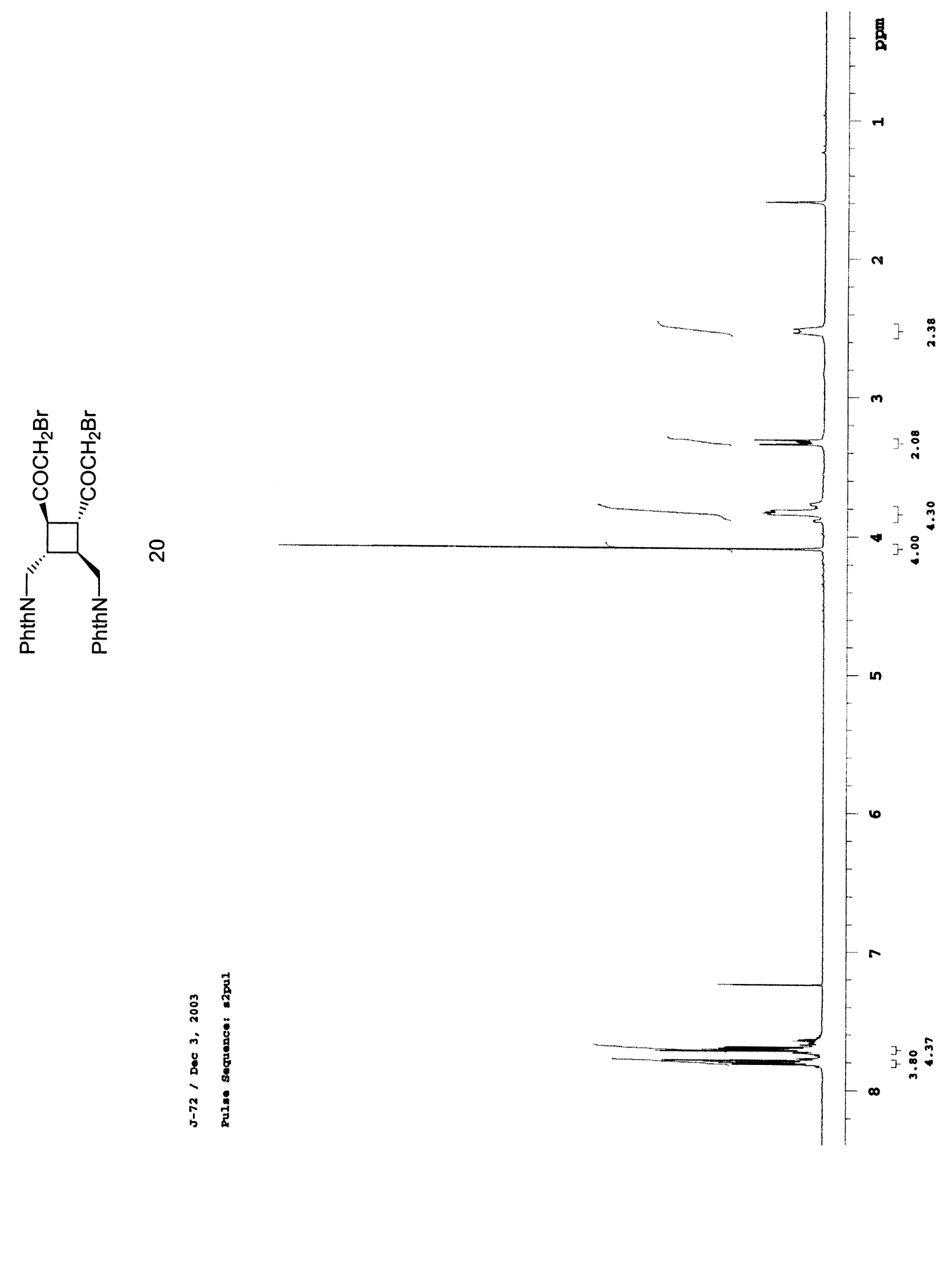




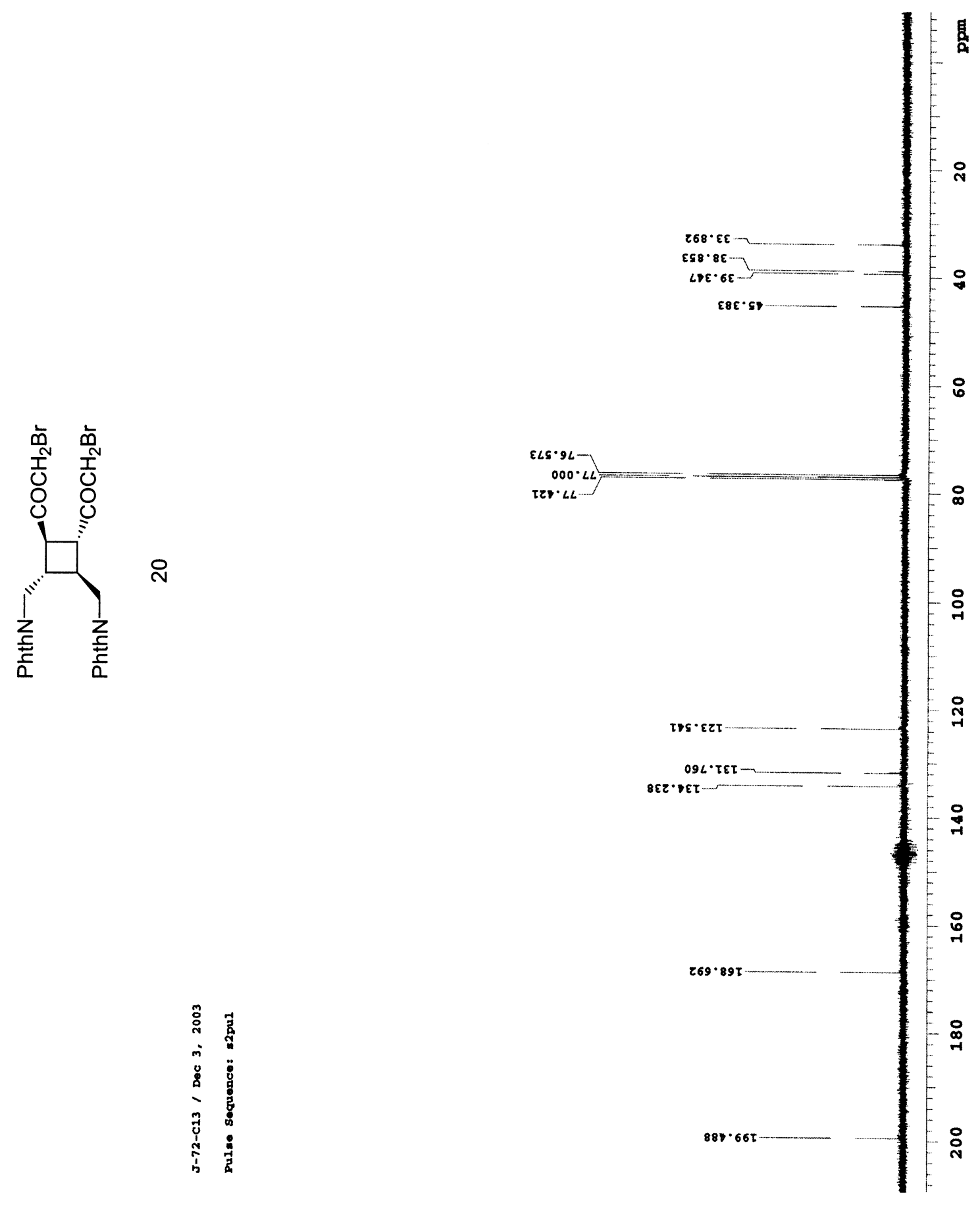

S16 


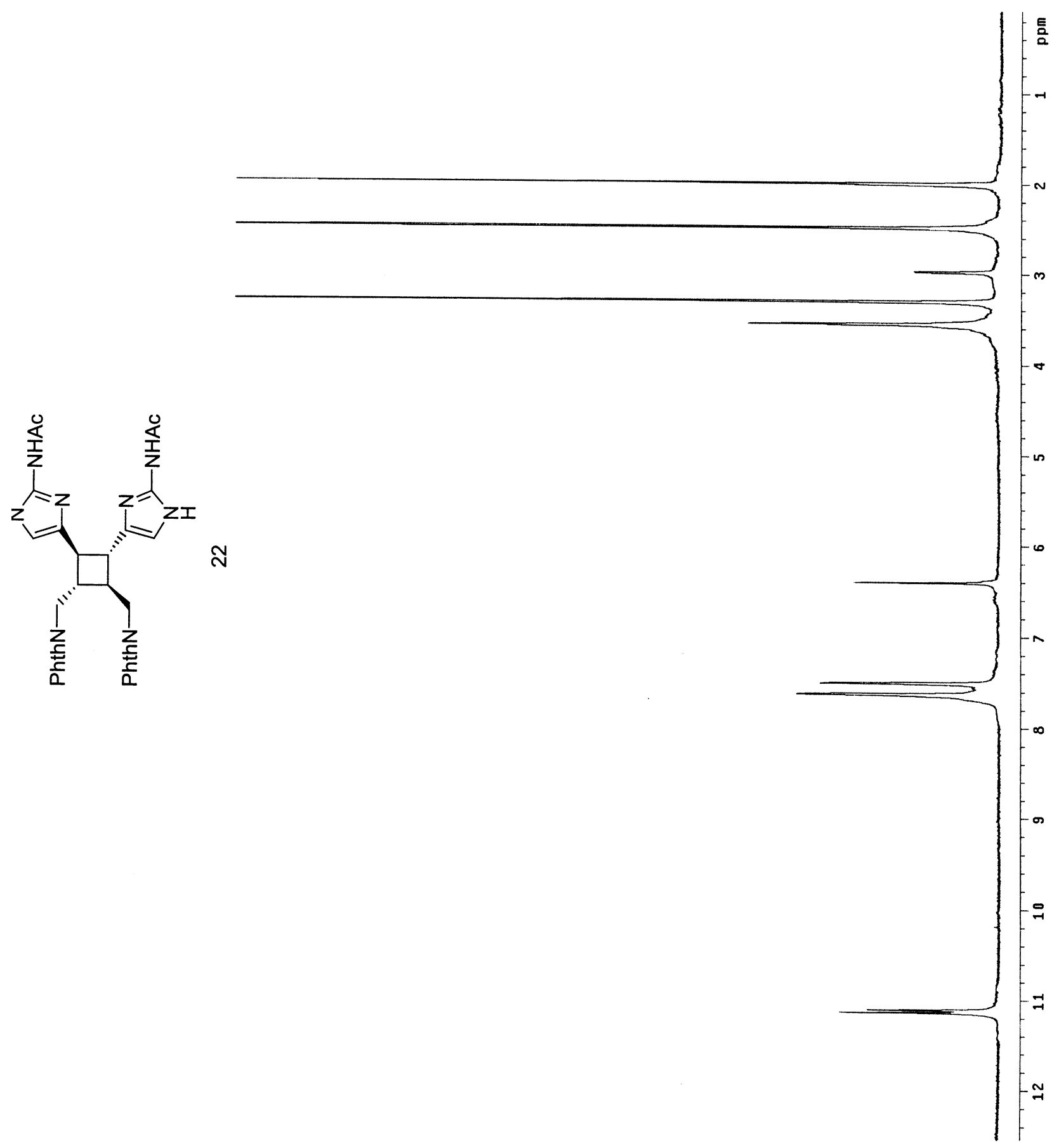






S18 


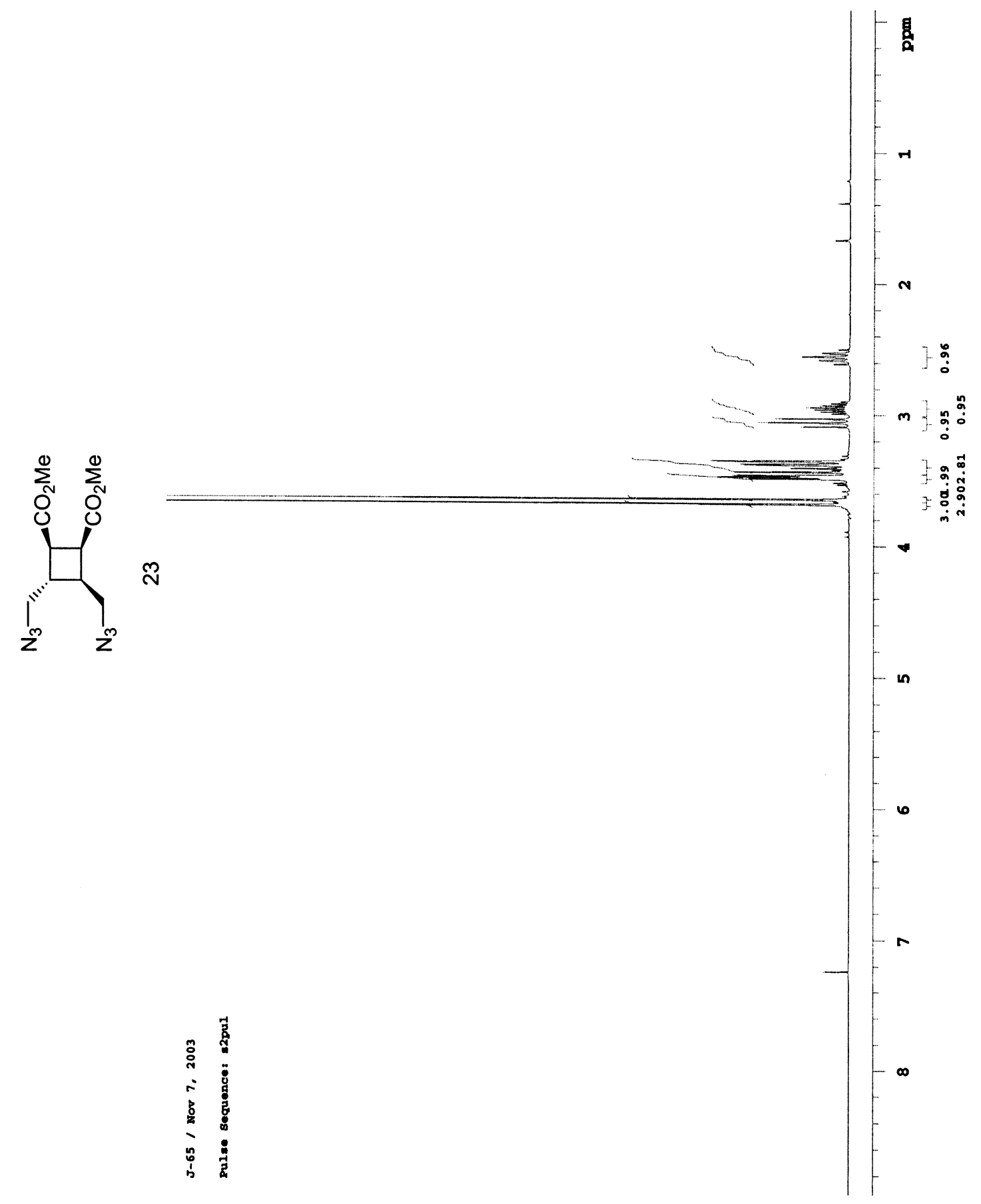

S19 


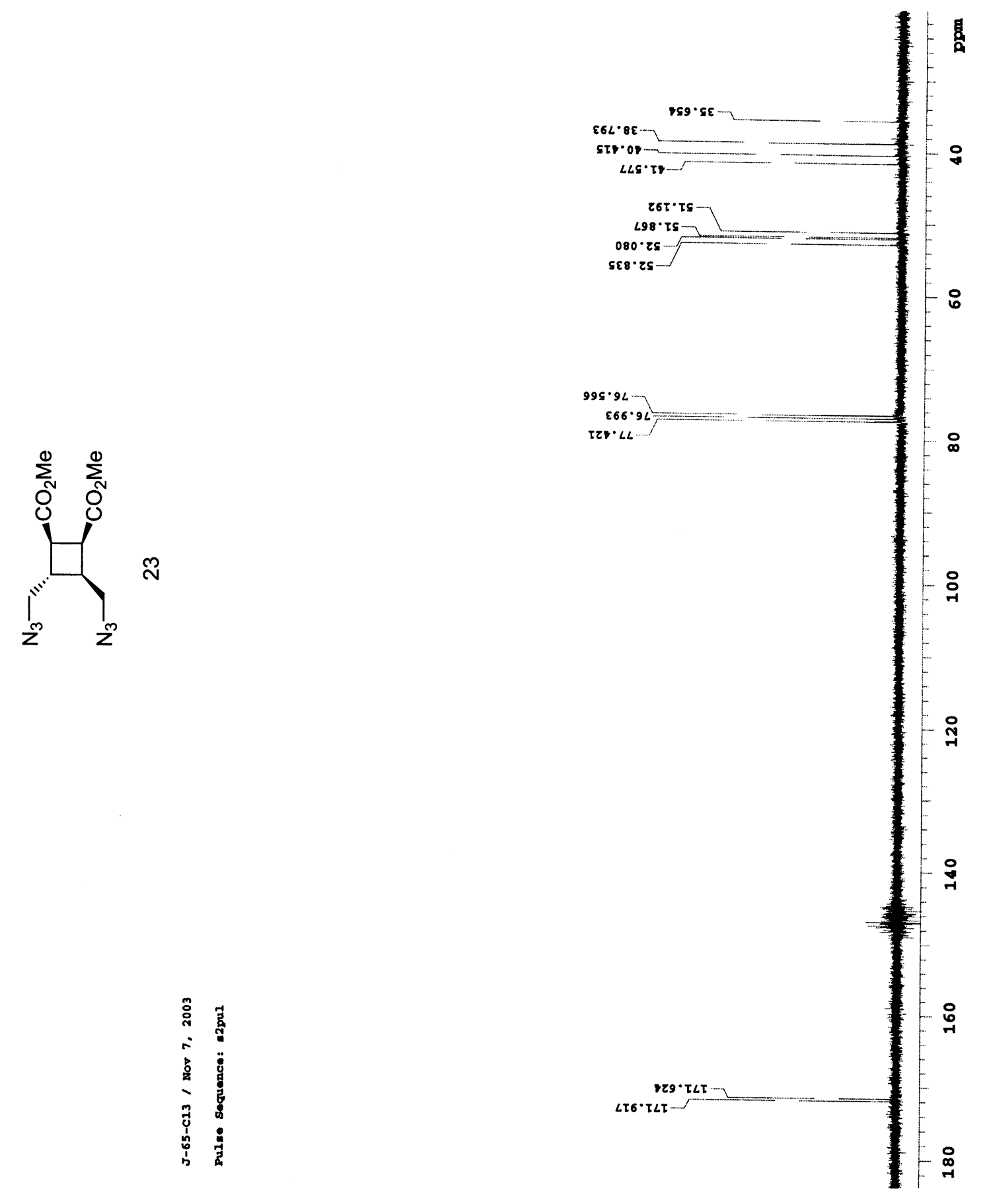

$\mathrm{S} 20$ 


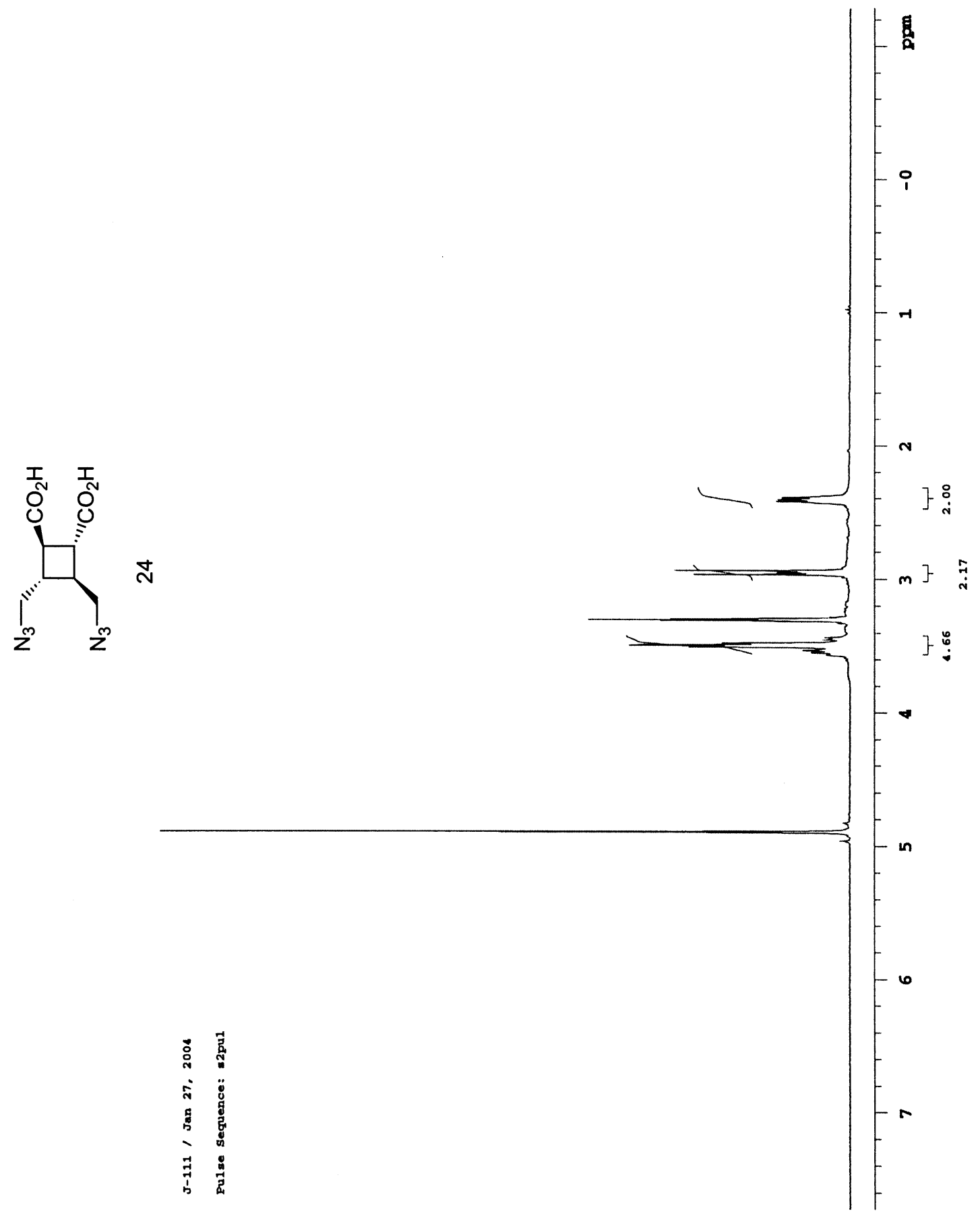




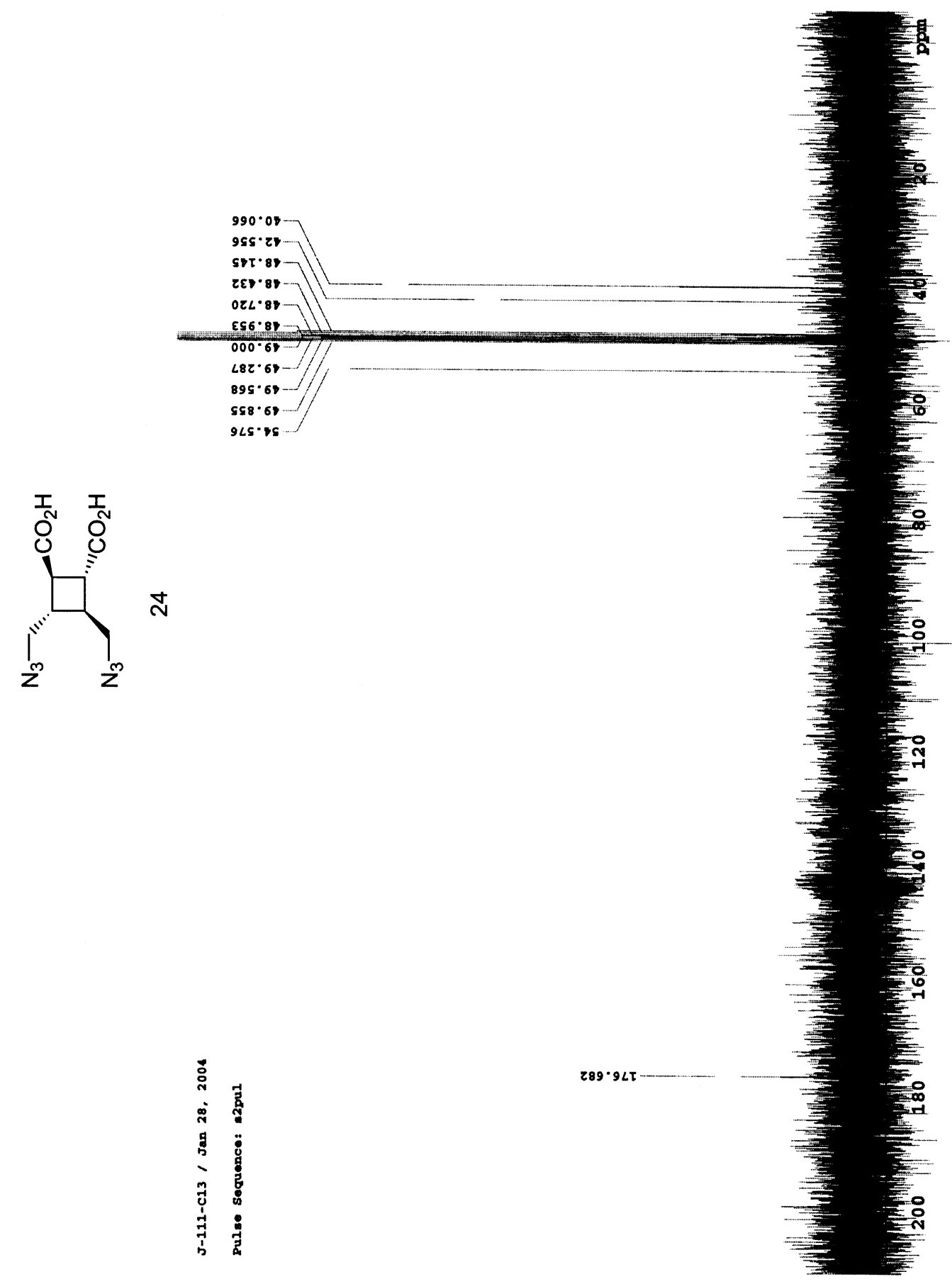

S22 


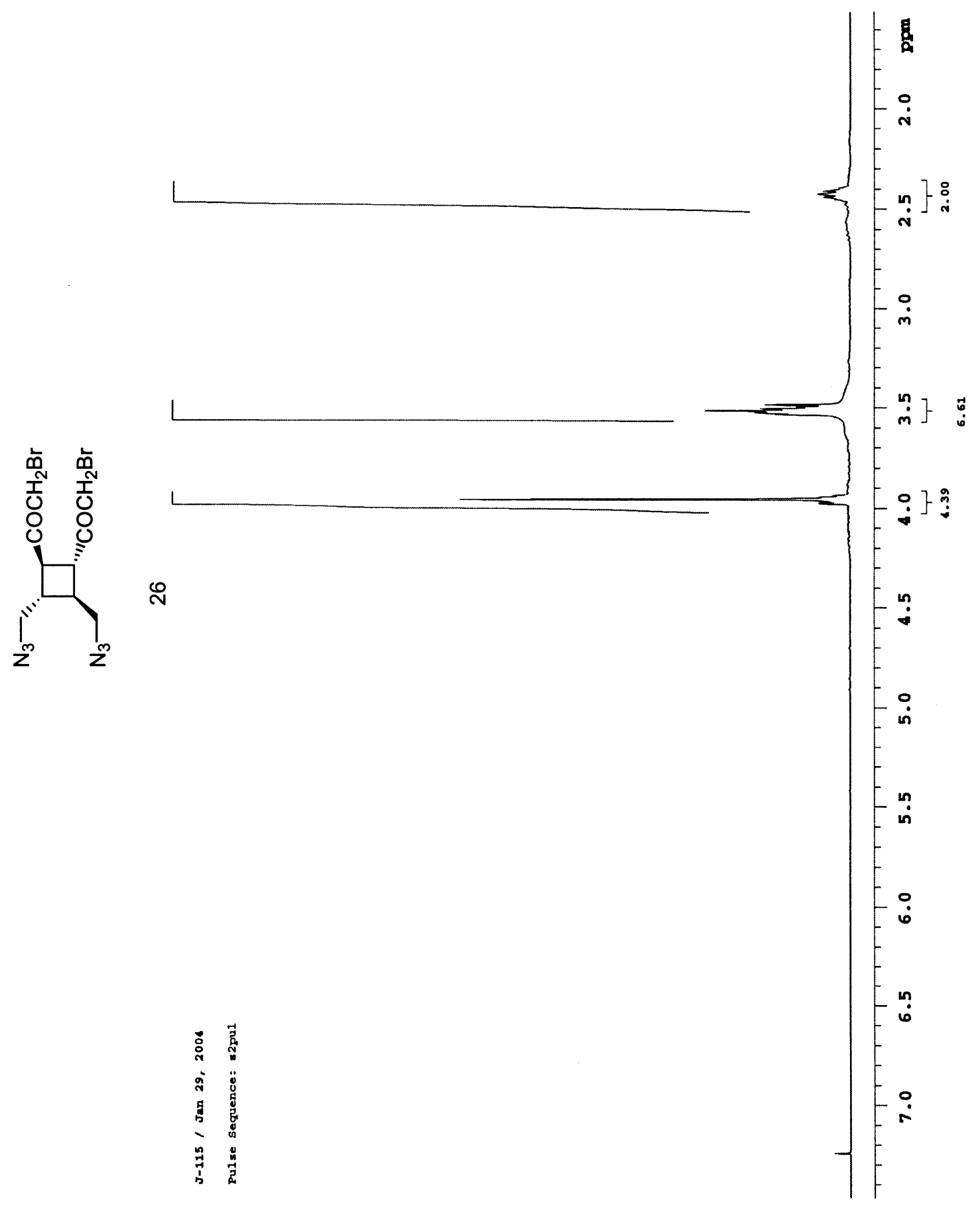

S23 

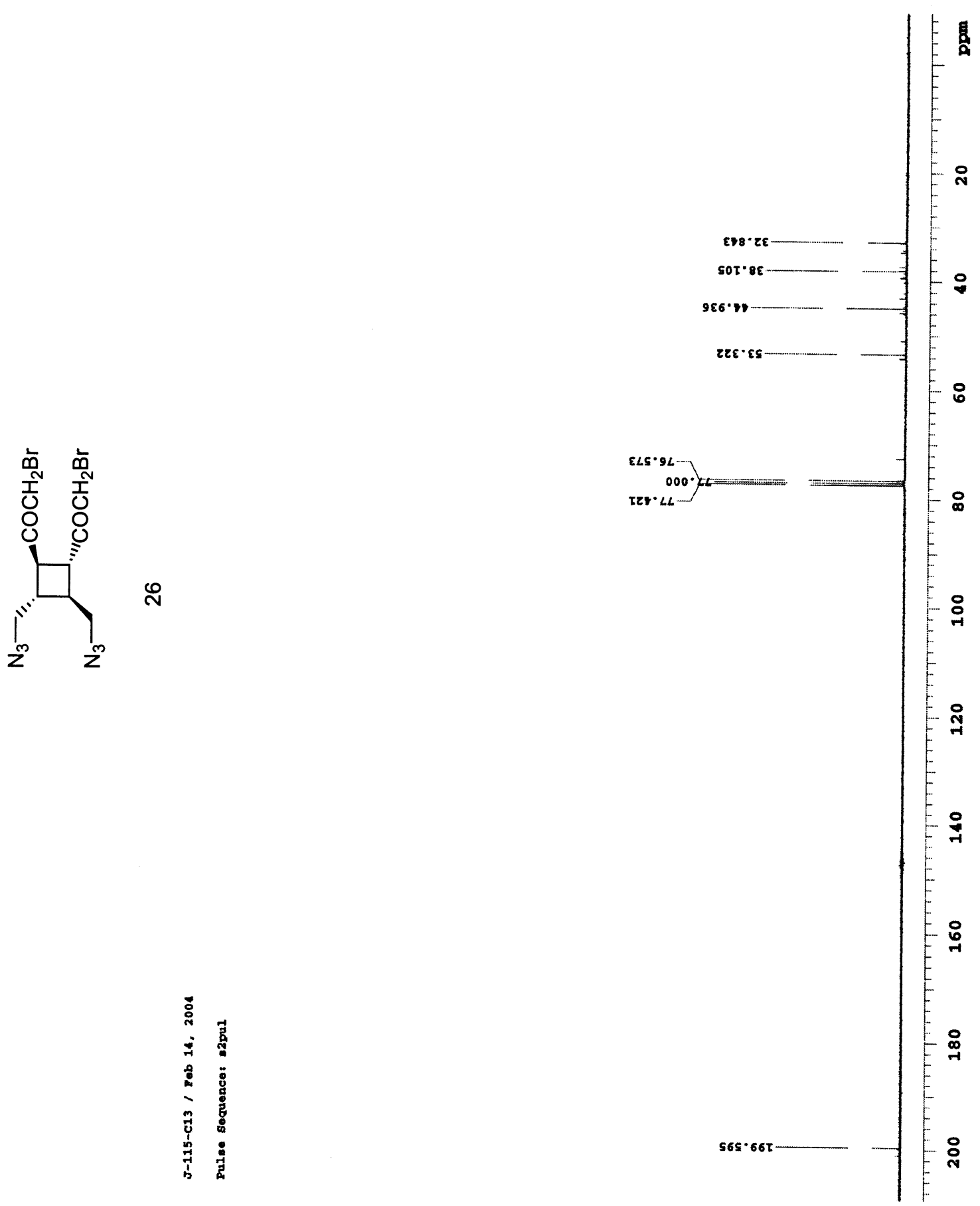

S24 


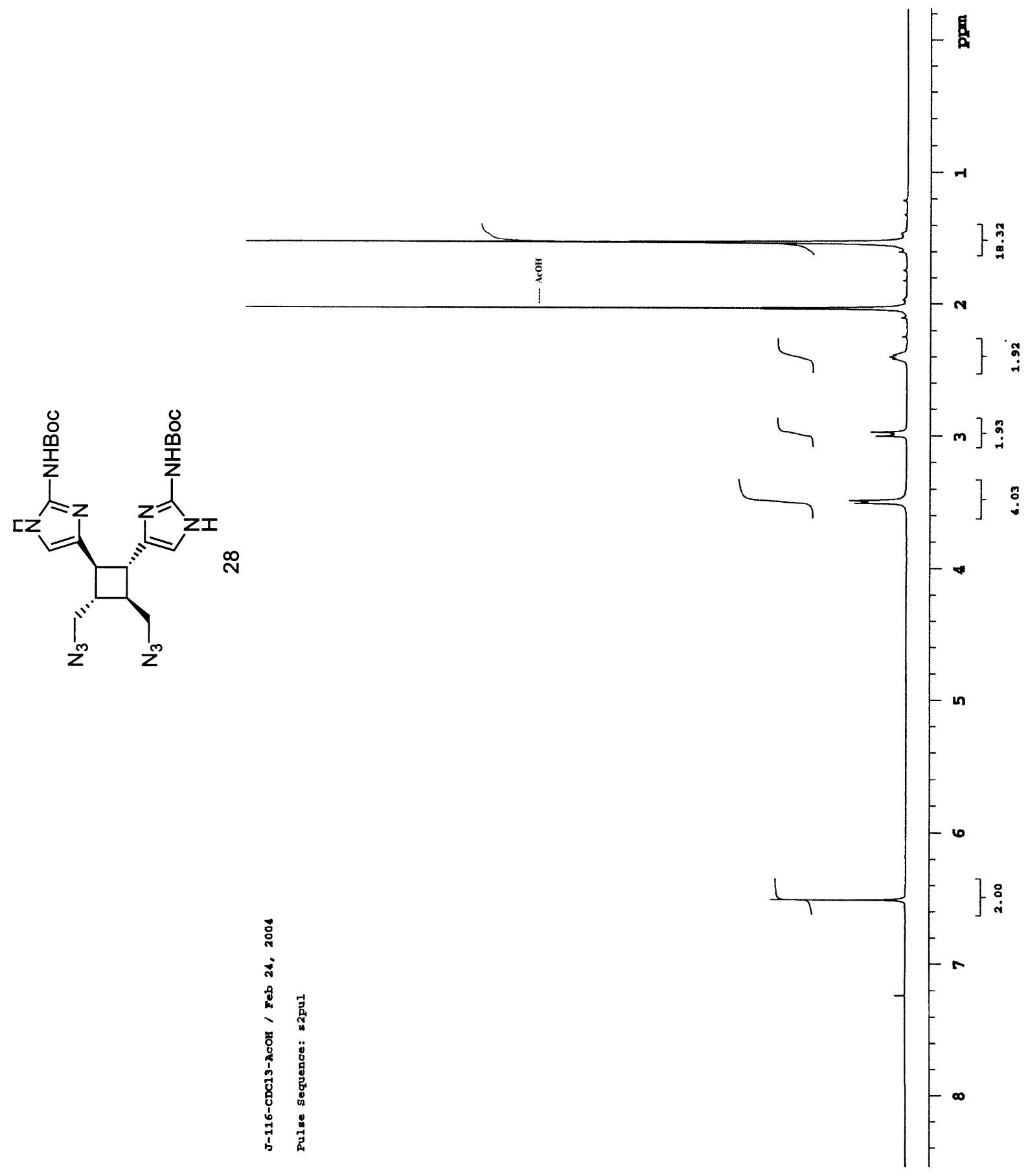

S25 

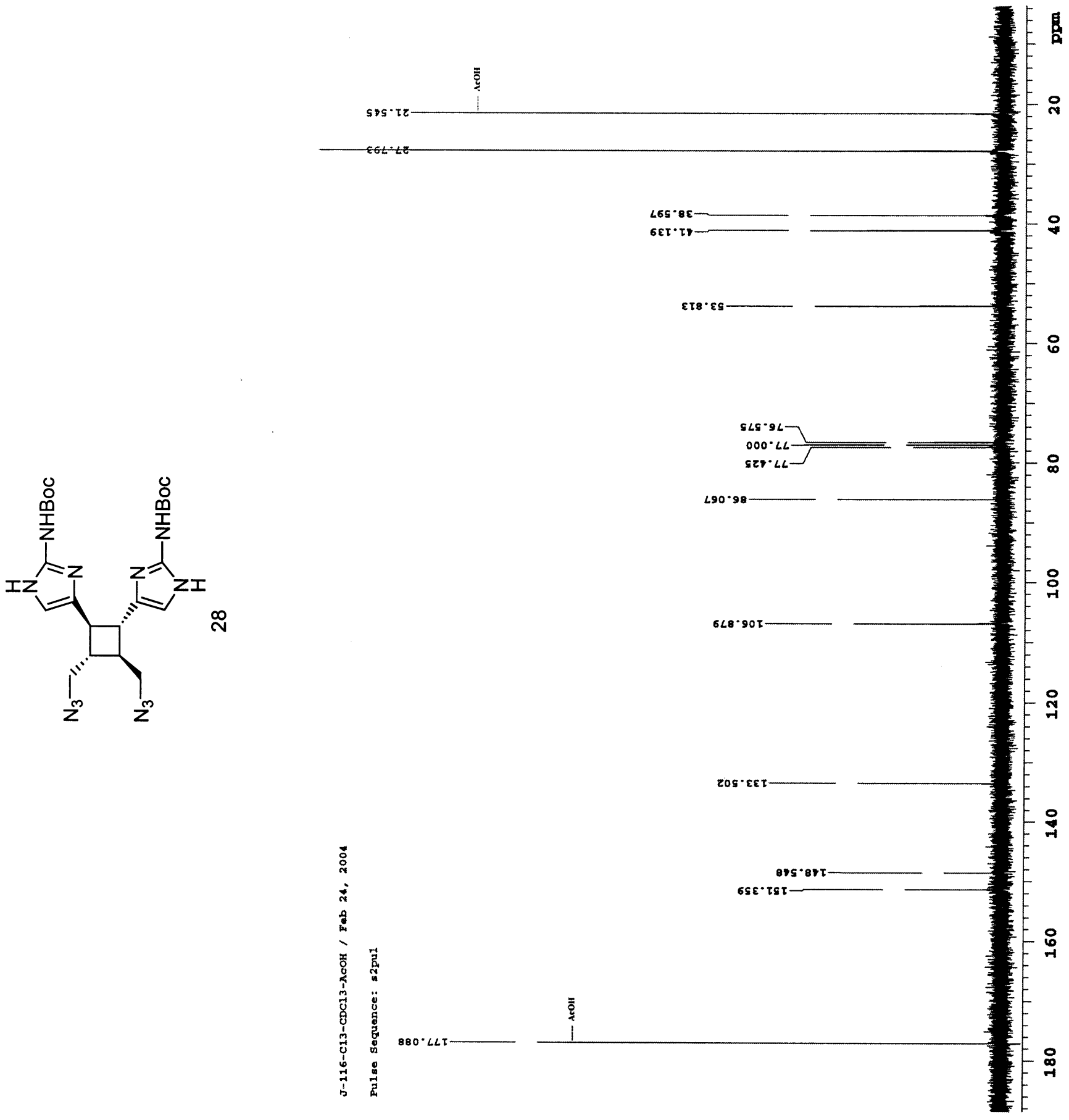

S26 


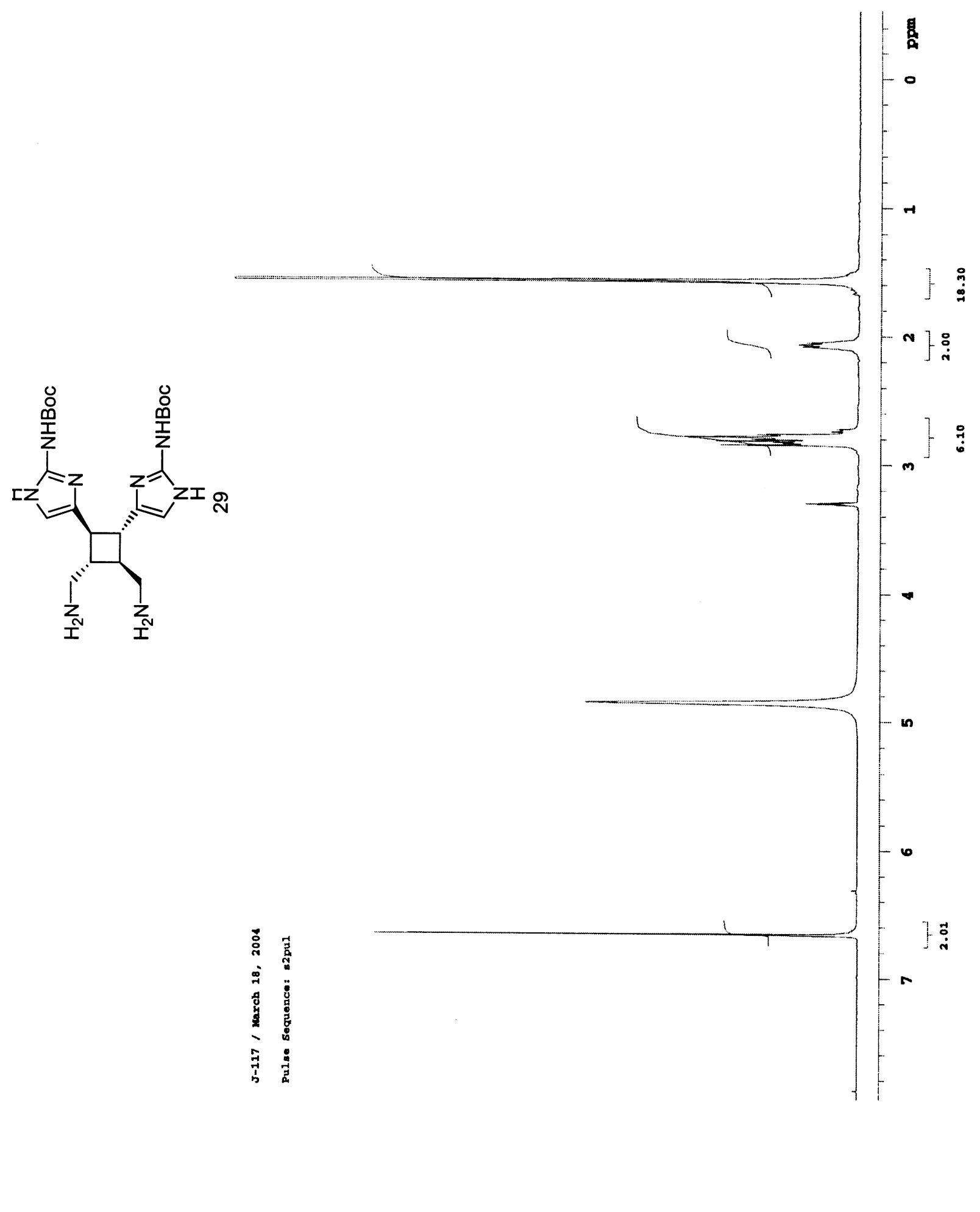




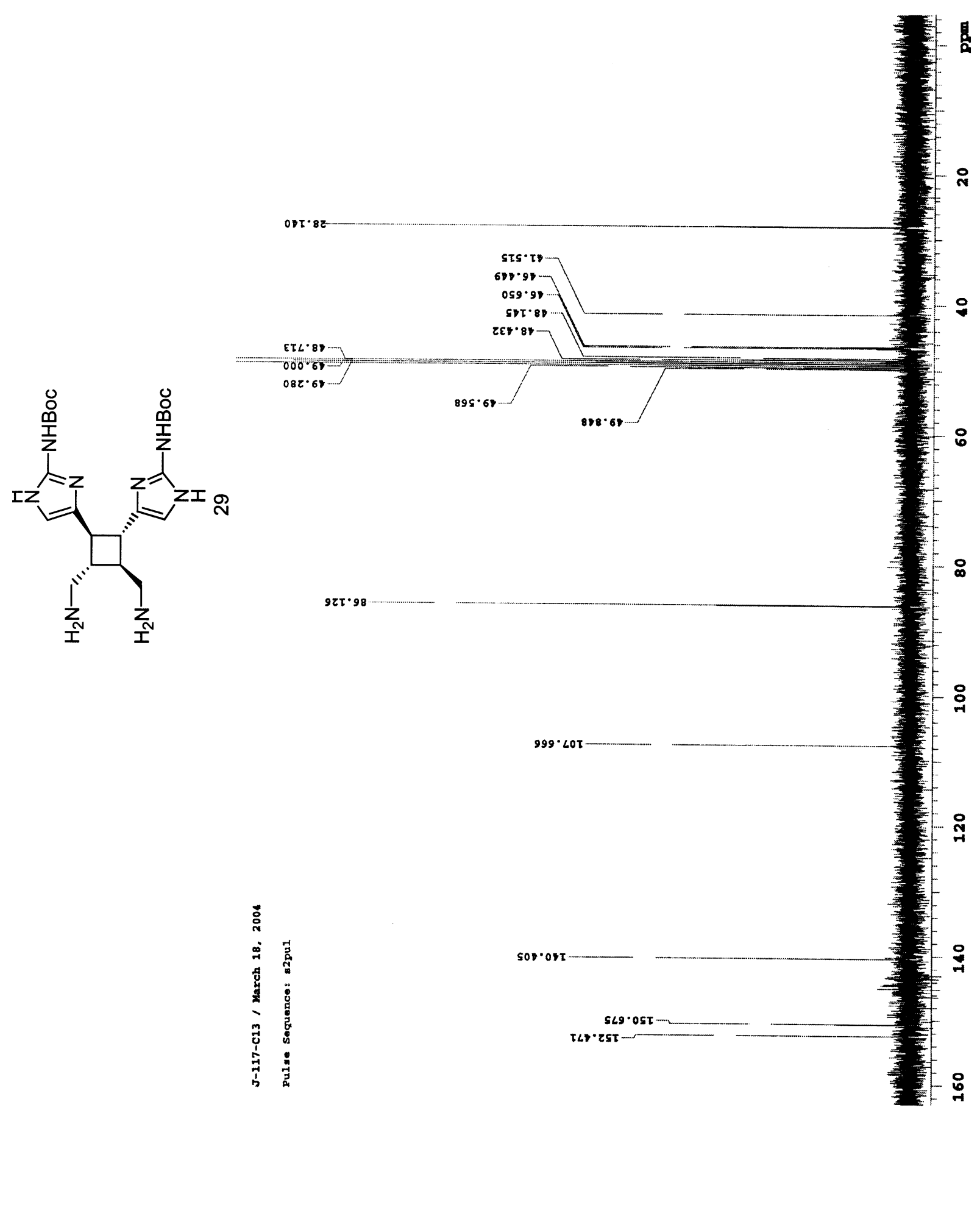




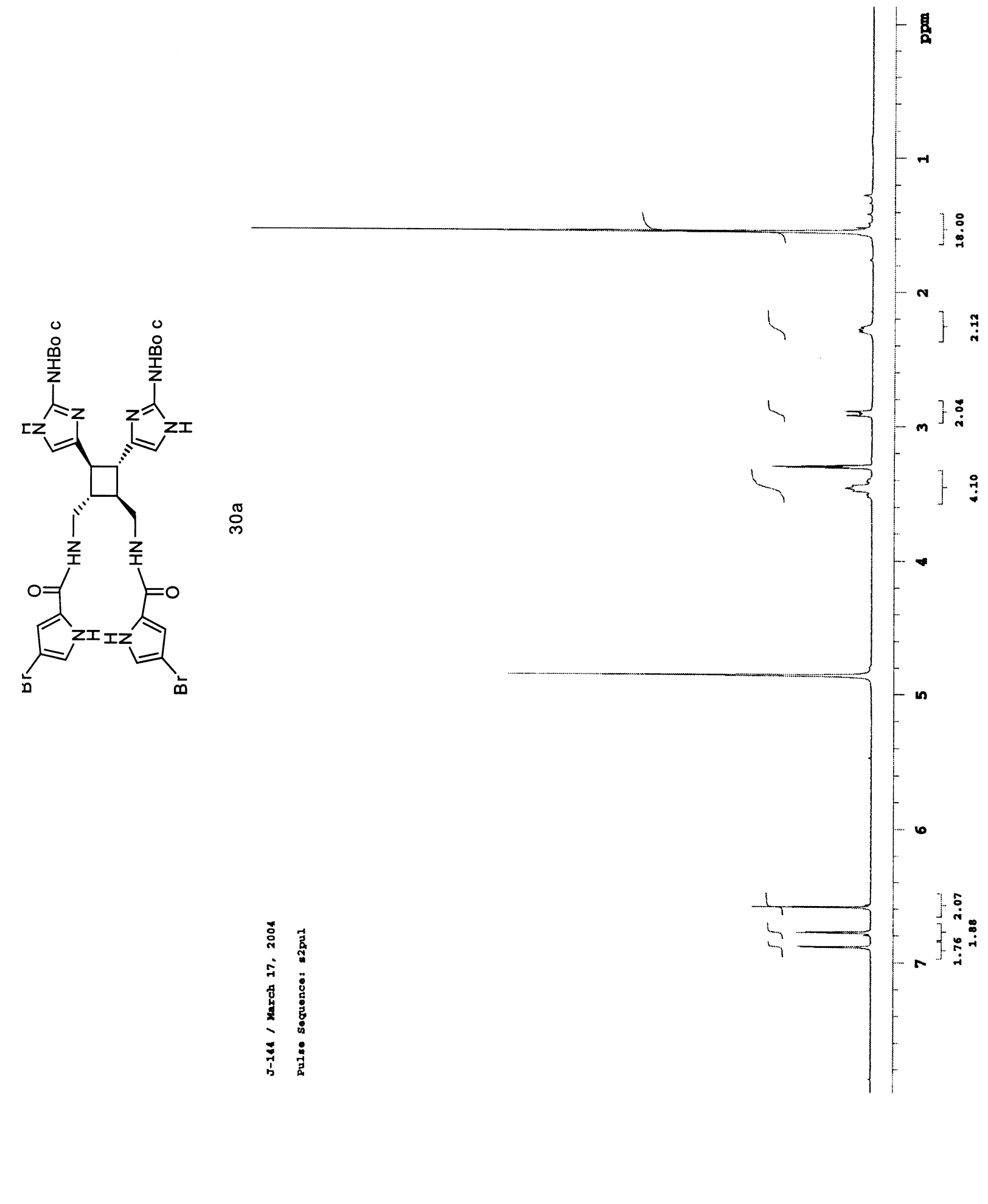



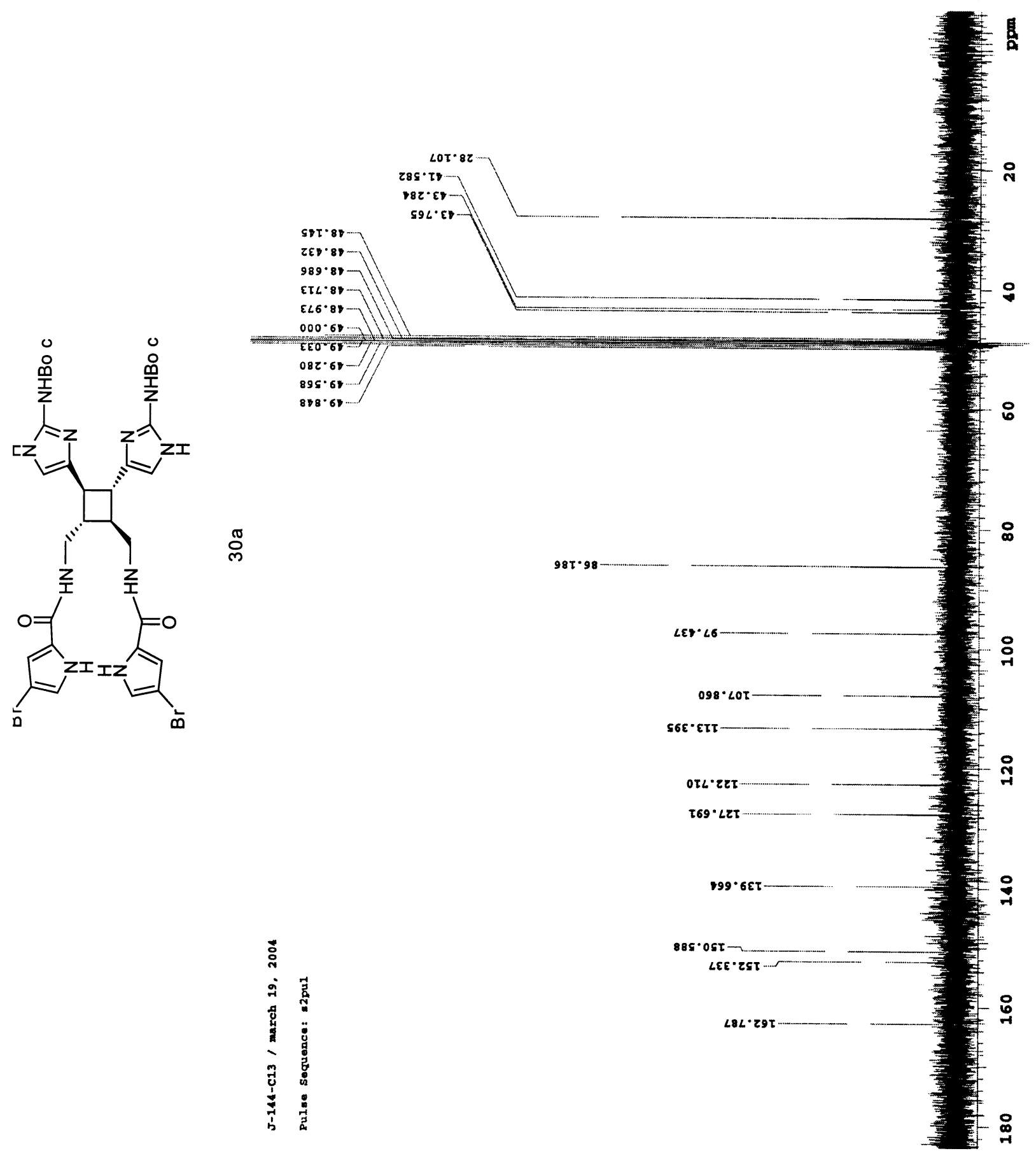


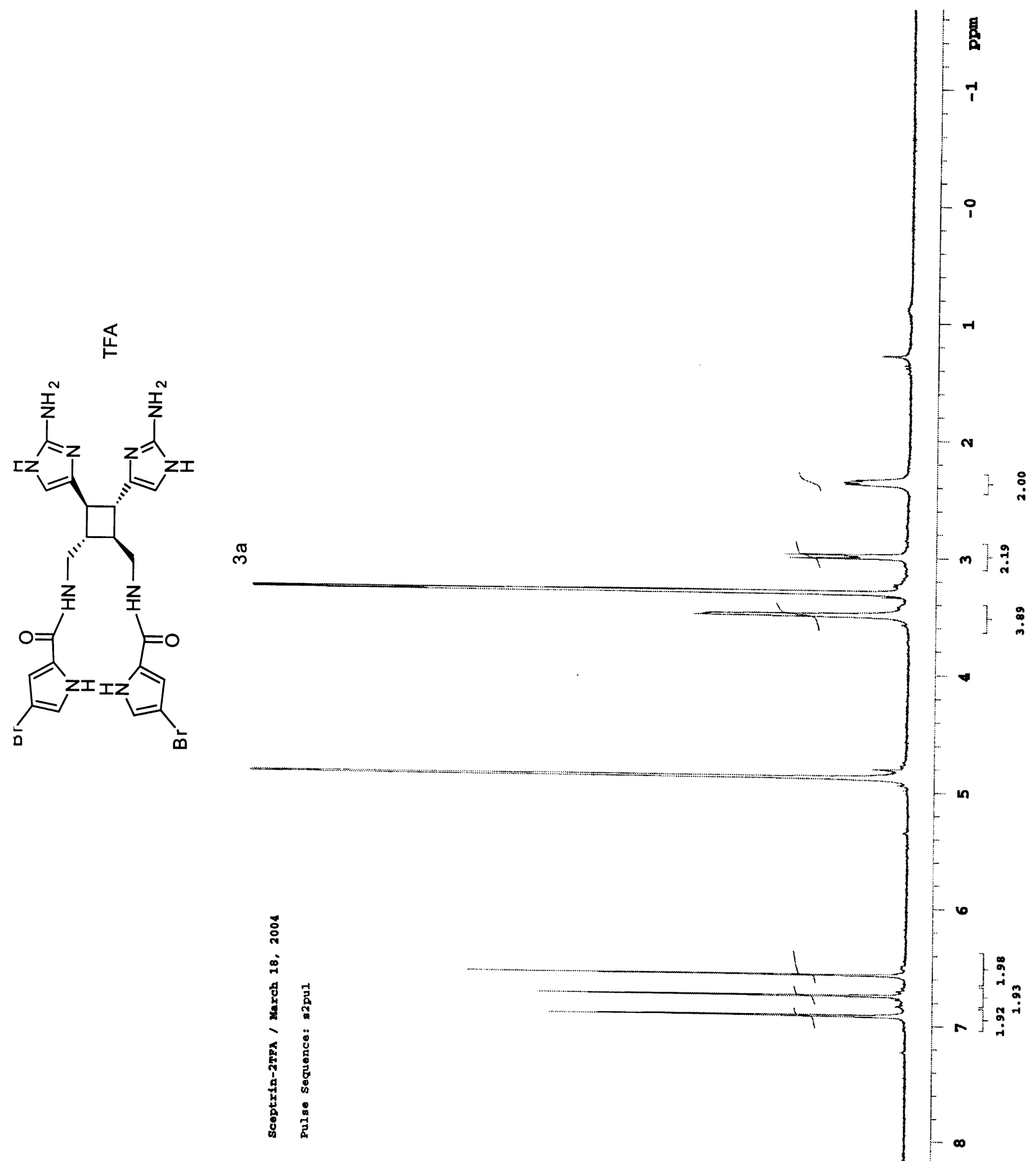

S31 

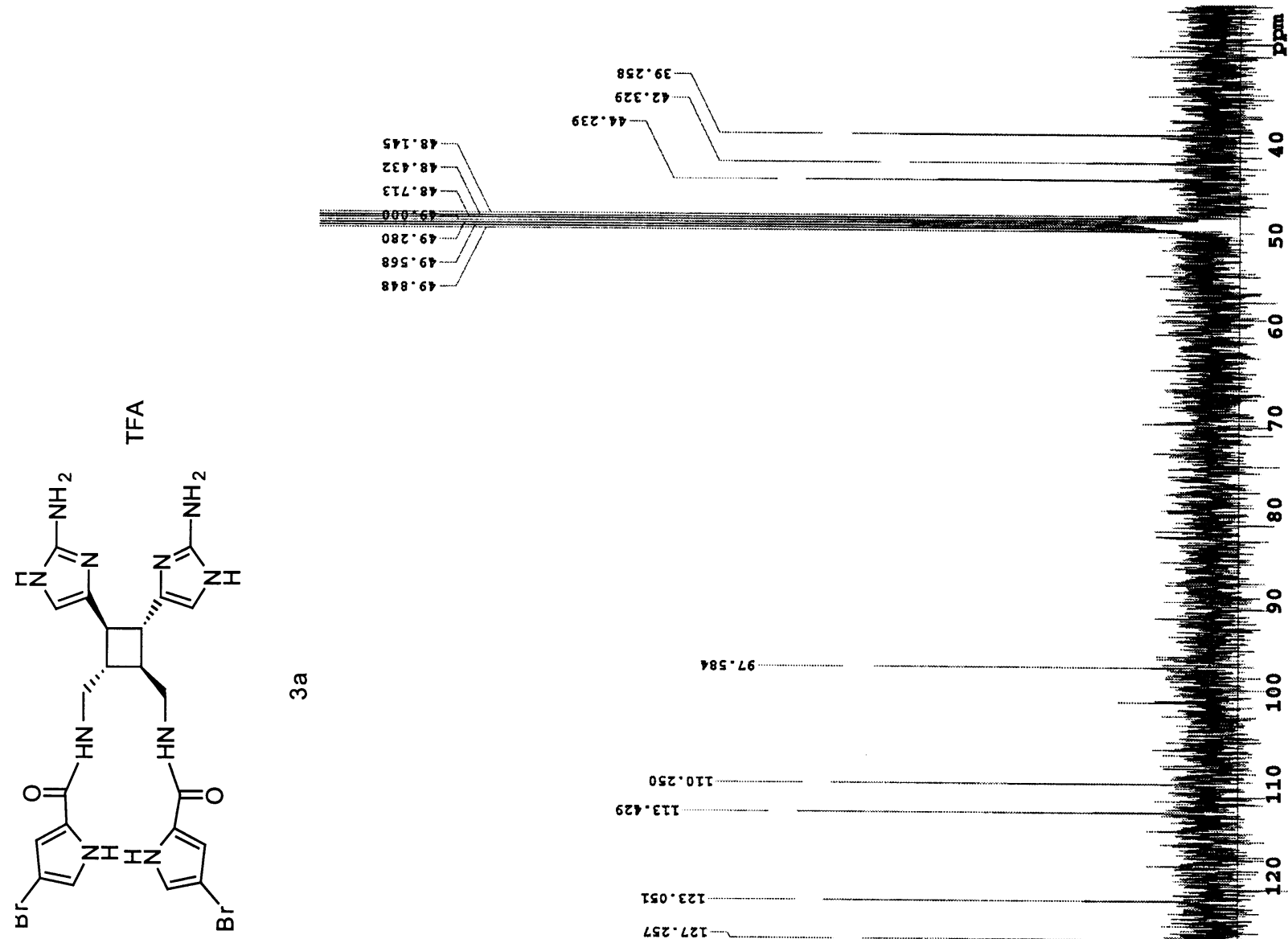

$082.67 \ldots 7$

895.65

$858 \cdot 67$

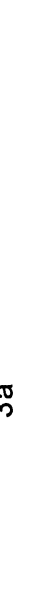

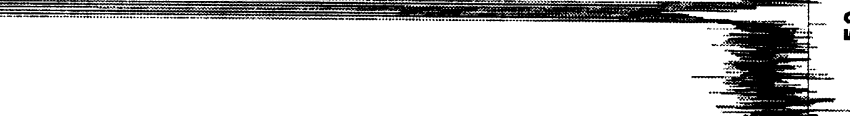

$=$ 

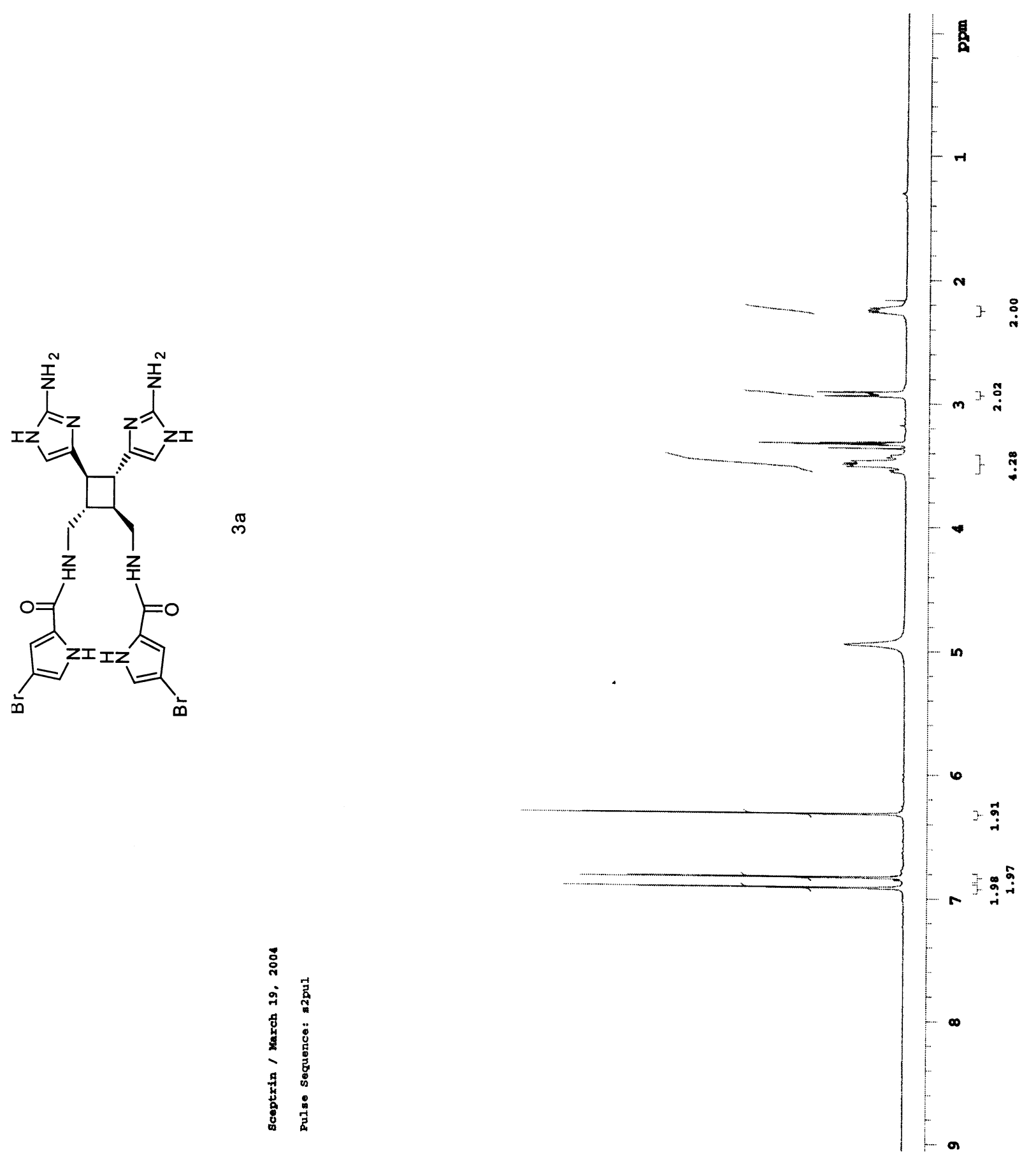

S33 


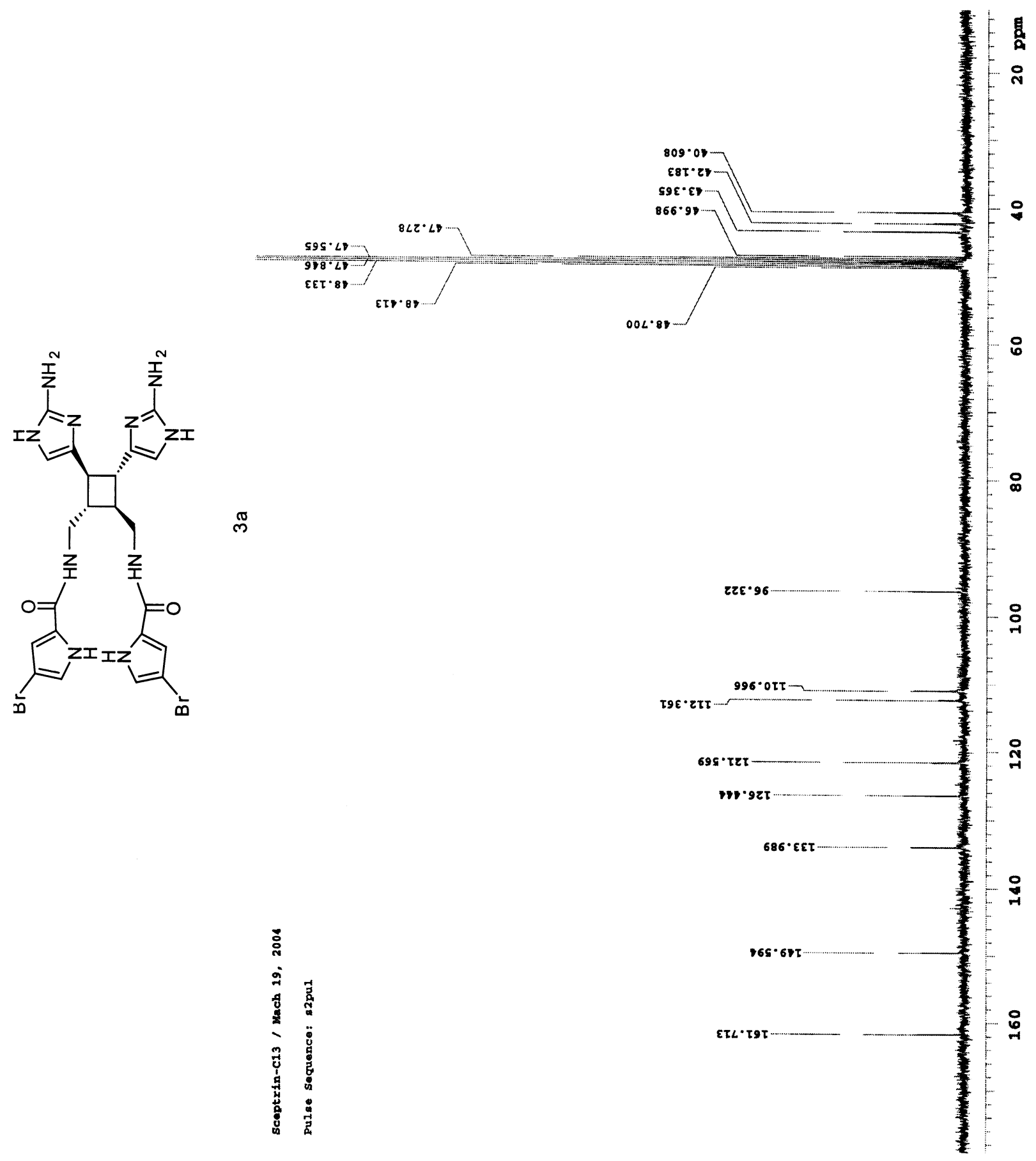




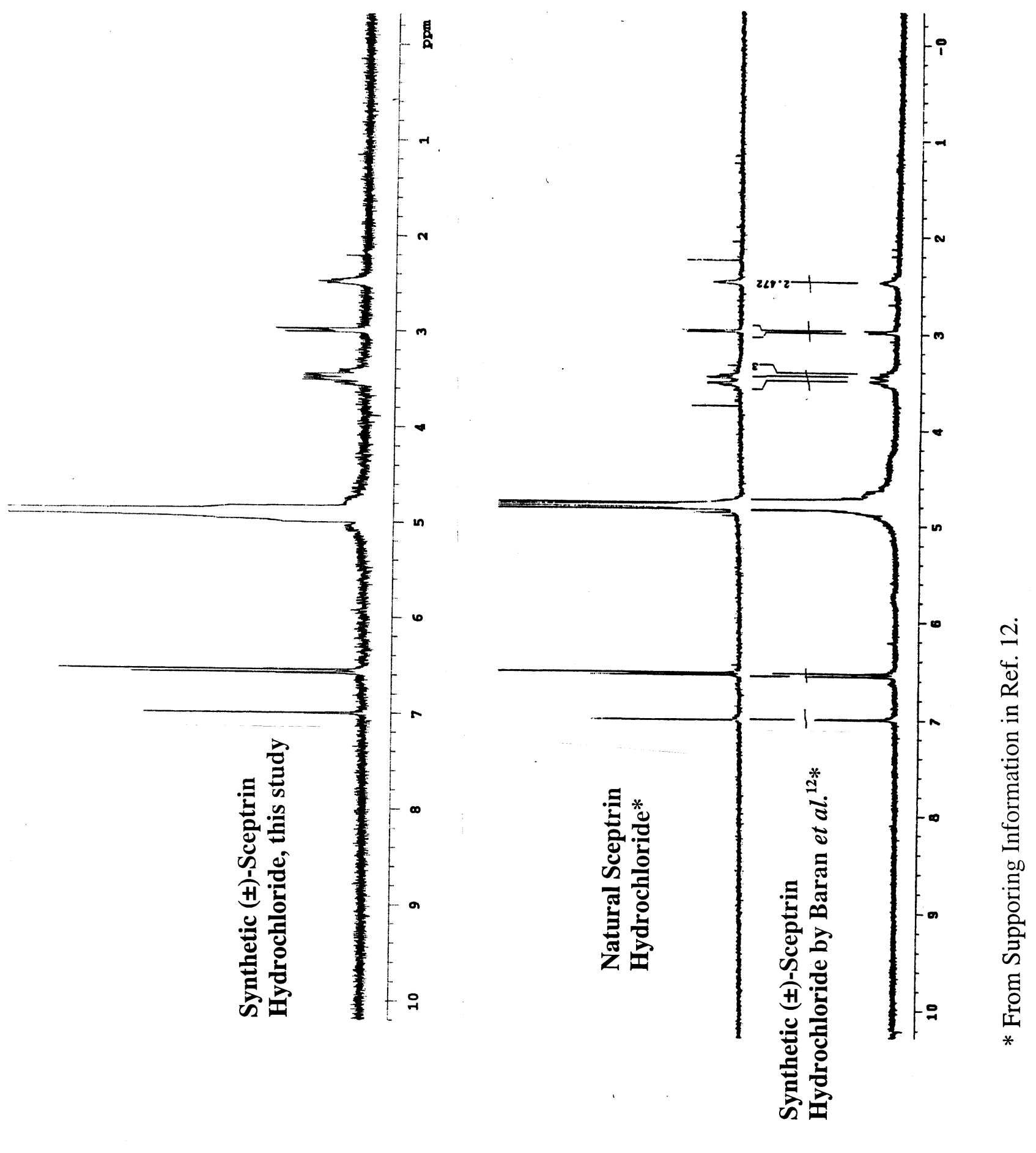




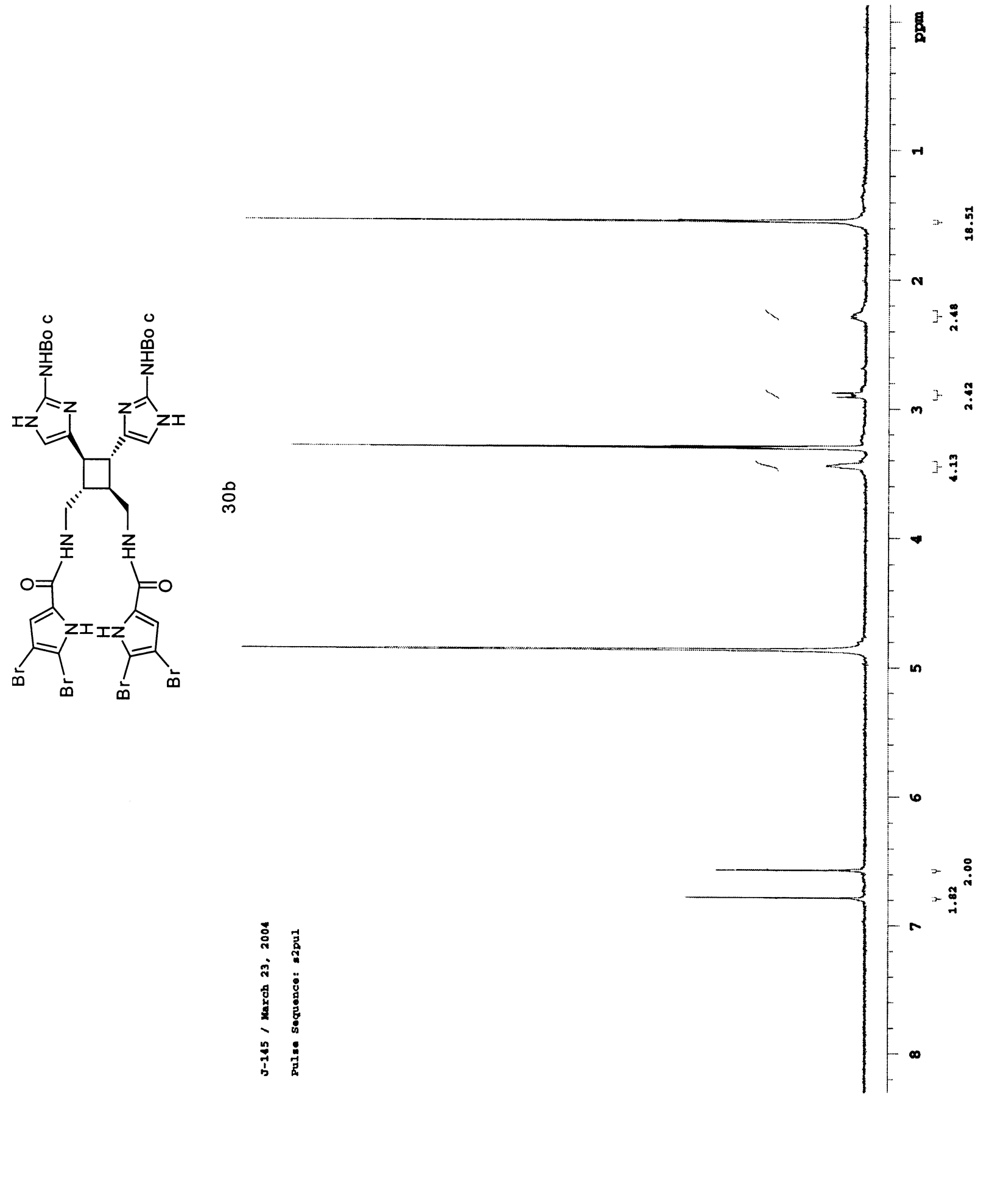



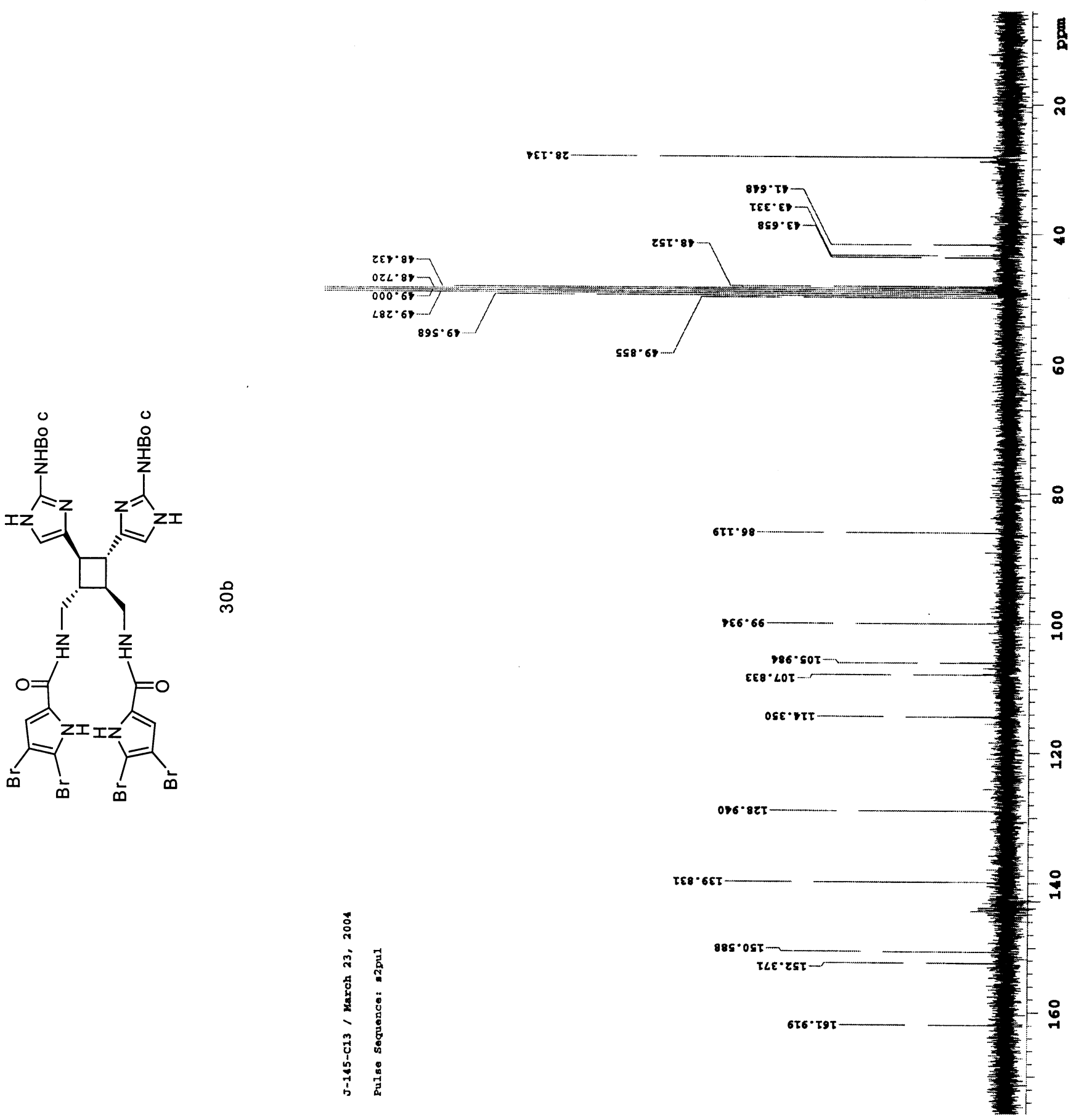


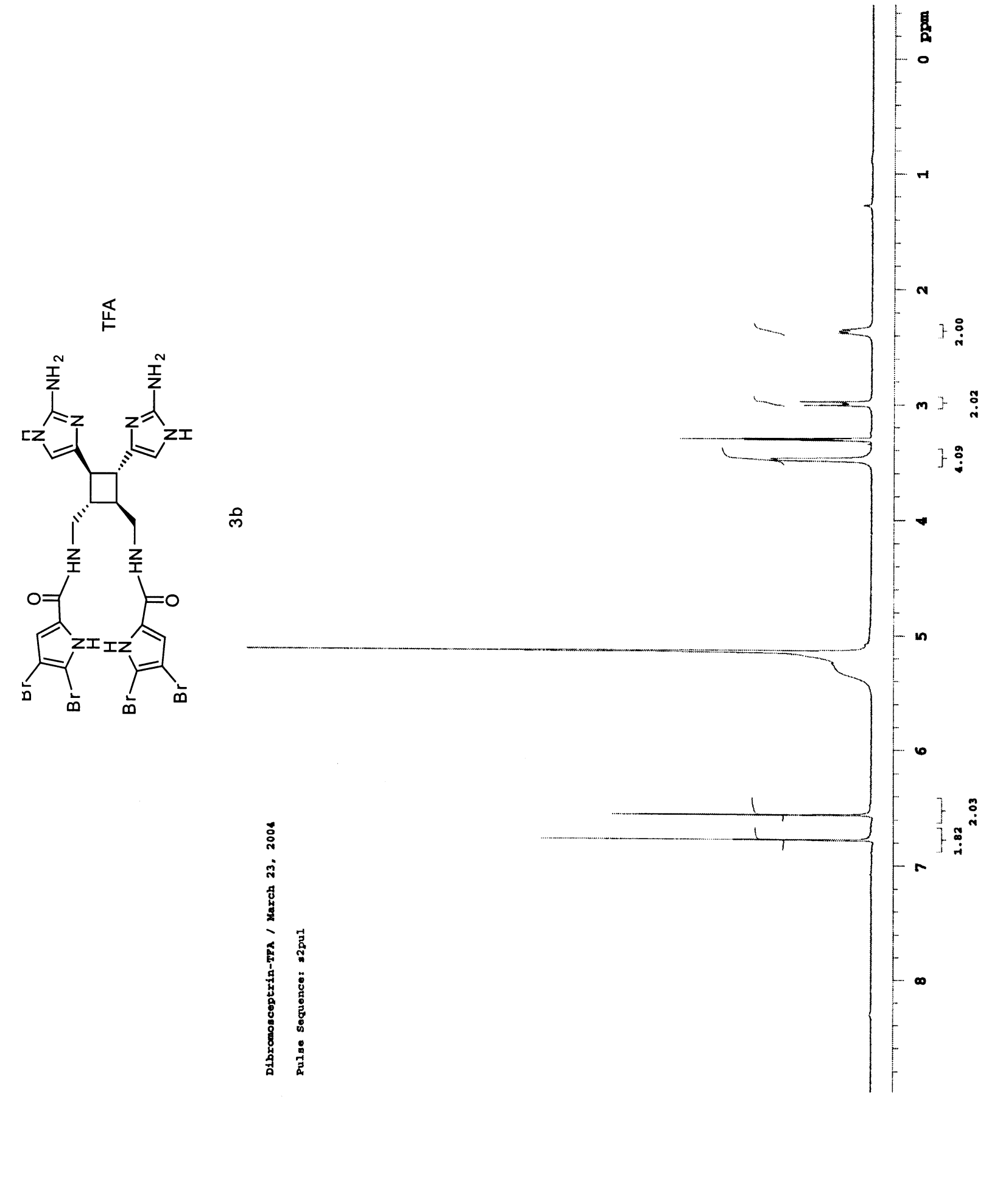




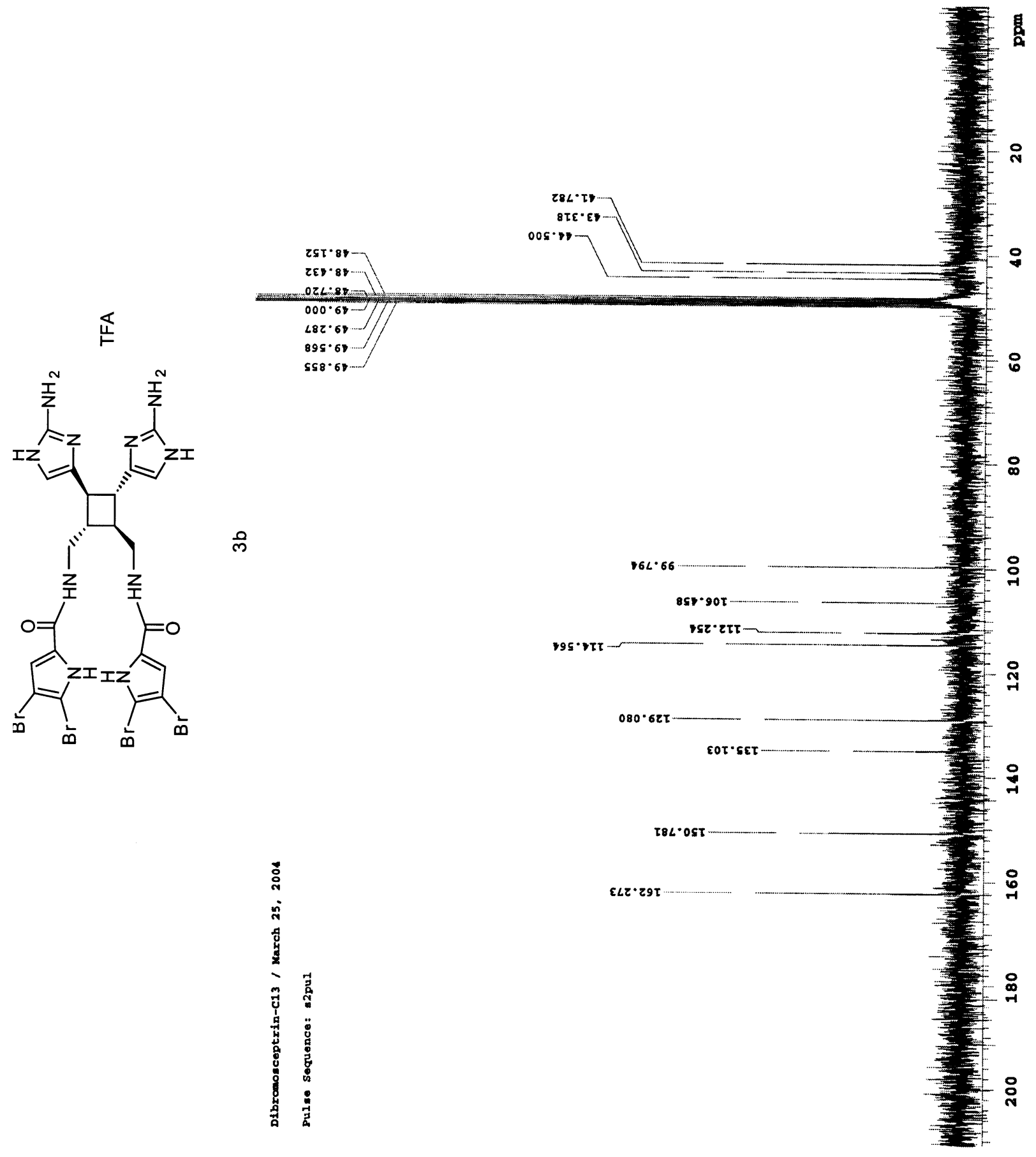




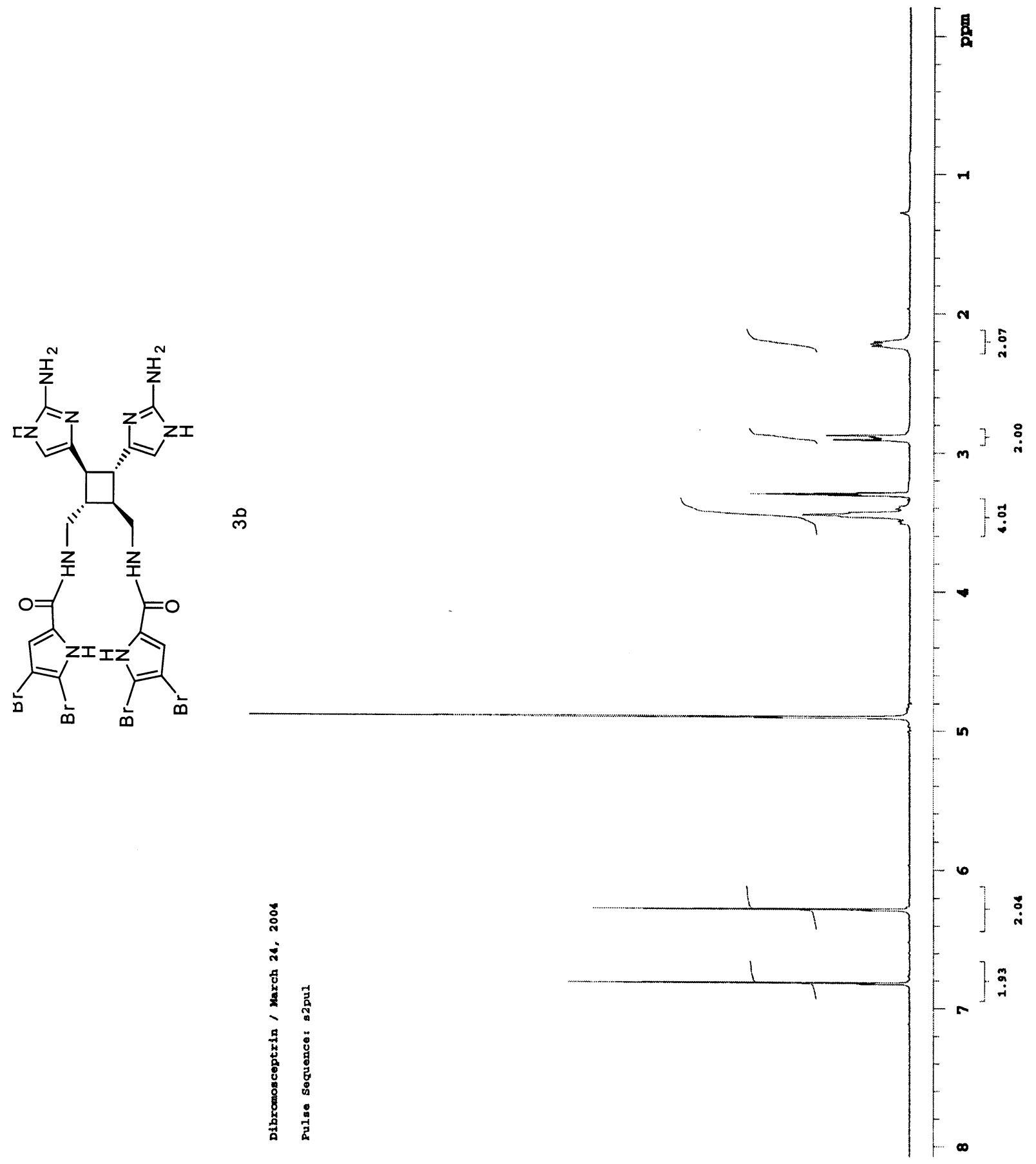

$\mathrm{S} 40$ 


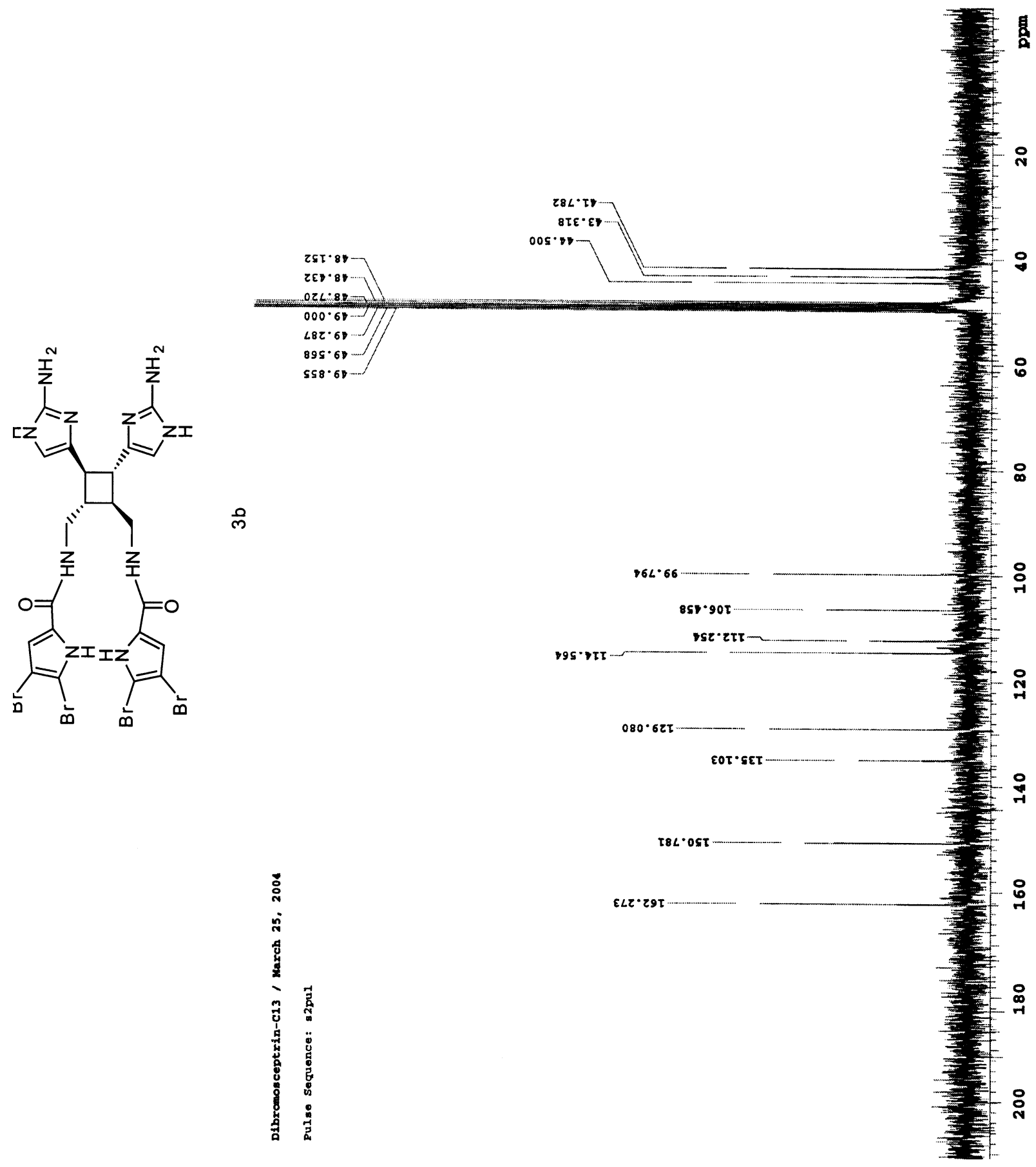




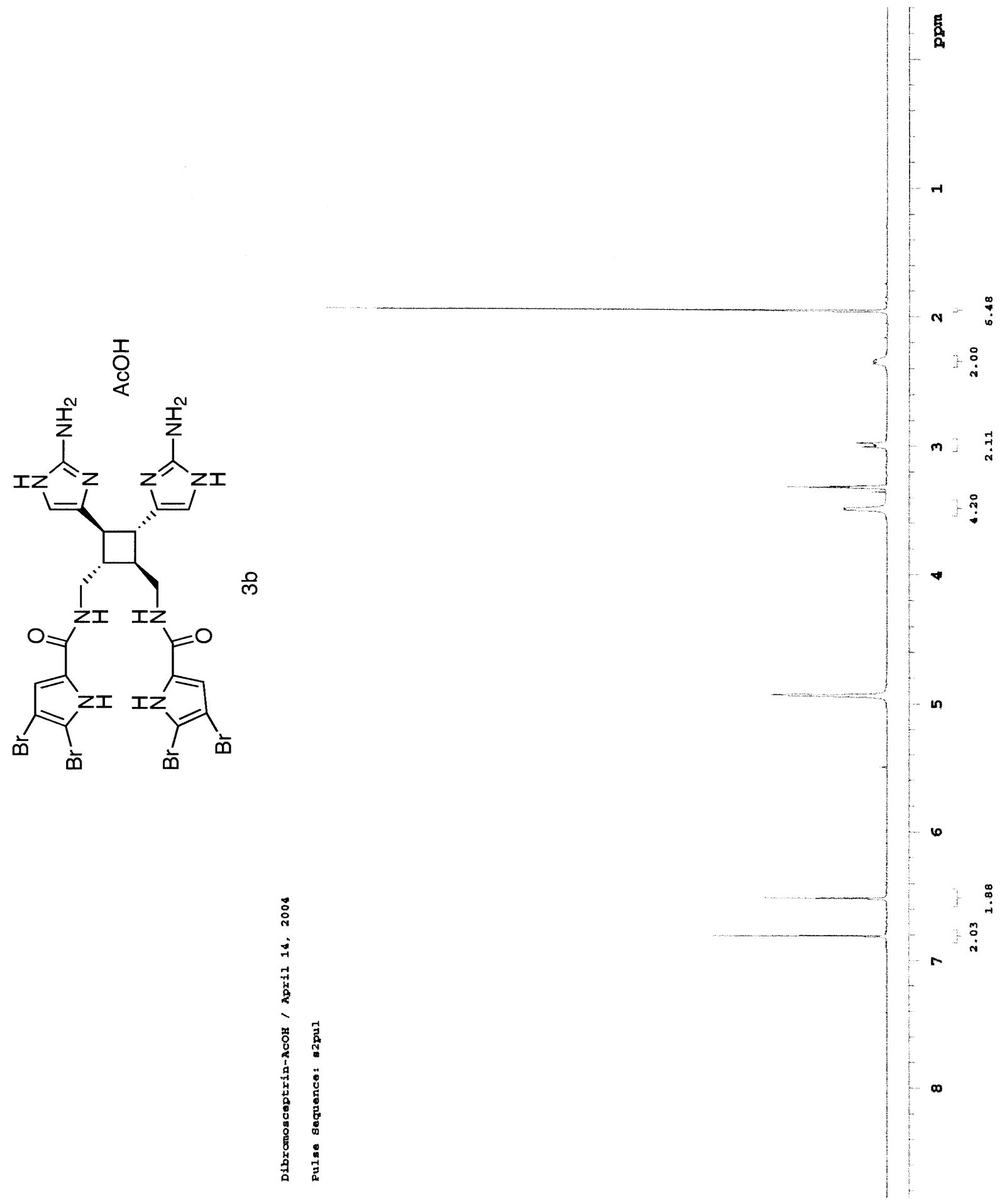

S42 


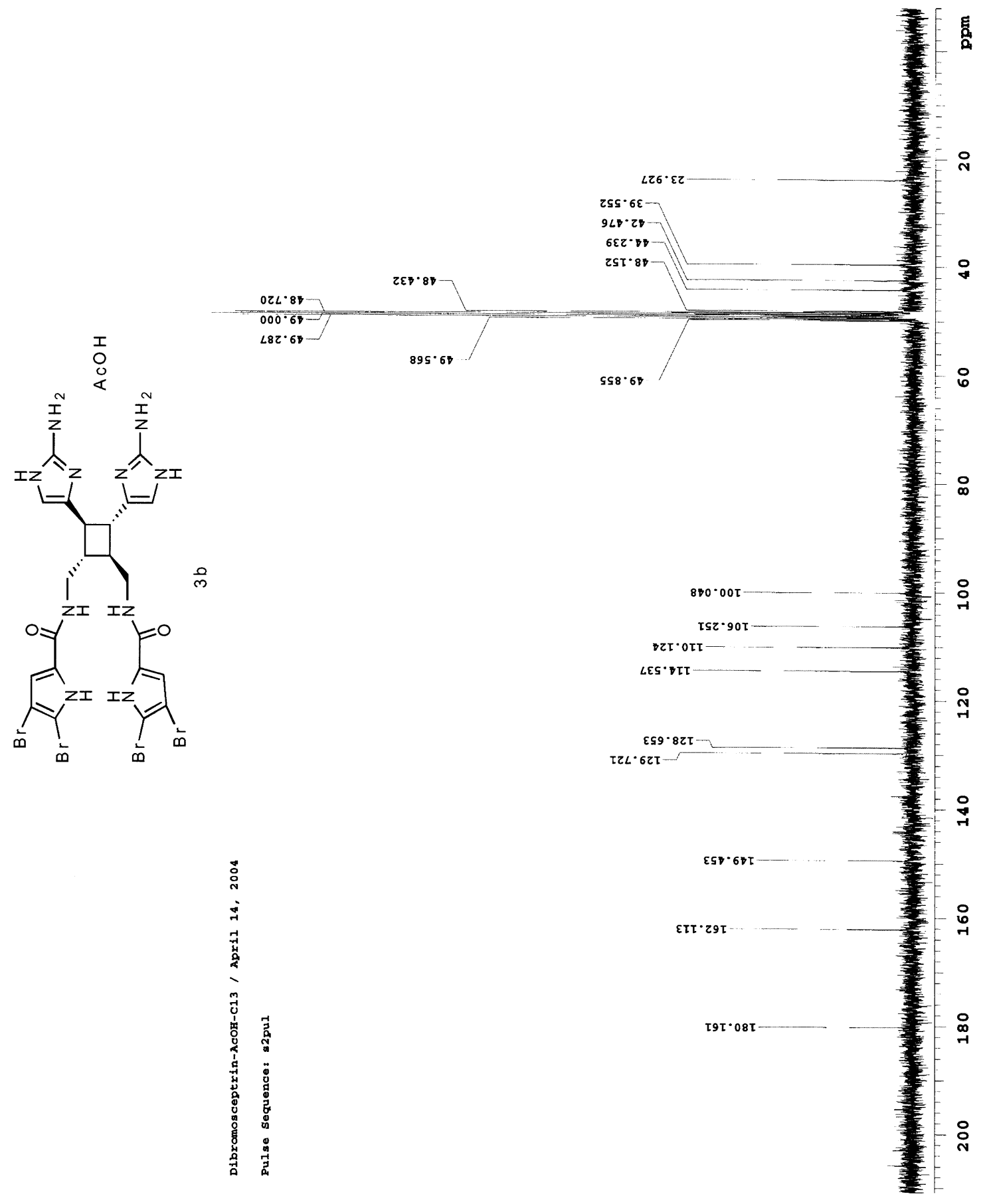

